\title{
Bioblockades join the assault on small G protein signalling
}

Helen R. Mott and Darerca Owen

Department of Biochemistry, 80, Tennis Court Road, Cambridge CB2 1GA, UK. Email: hrm28@cam.ac.uk, do202@cam.ac.uk; Phone: +44-1223-764824/5

Keywords: Ras; peptidomimetic; G protein; therapeutic; macrocycle 


\begin{abstract}
Inhibition of Ras signalling has been a goal almost since its central role in cell signalling and its deregulation in disease were discovered. Early attempts at inhibiting its post-translational modification using peptidomimetics were successful in cell culture but failed spectacularly in clinical trials, making industry wary of targeting this critical oncoprotein. Small molecule inhibition of the protein-protein interactions involving Ras has also been difficult due to the nature of the interaction interface. Recent improvements in design, synthesis and selection of stabilised peptides, peptidomimetics and macrocycles have suggested that these biologics may represent a new hope in Ras inhibition. Here we review the various ways in which Ras has been targeted with these molecules. We also describe work on related small $\mathrm{G}$ proteins of the Ras superfamily, since many of the principles may be applicable to Ras, and these also provide inhibition of pathways downstream of Ras.
\end{abstract}




\section{Introduction}

While innovative technologies for application to therapeutic discovery are always necessary and welcomed, never has this been truer than in the field of Ras-driven disease and especially cancer. Most attempts to utilize conventional targeting strategies are widely accepted by the field to have failed. It would therefore seem an obligation for the research community to investigate the utility of any new approach, even against the tide of prevailing 'wisdom', if it has the potential to add to the armamentarium. Although antibody-based biologics hold their own in the appropriate context, peptide based therapeutic strategies have long been the poor relation of small molecule therapeutics, especially for intracellular targets. However, advances in stabilization and delivery have brought new hopes for this modality and pioneering attempts to modulate Ras signalling pathways using new peptidomimetics are underway.

It is accepted that intracellular protein-protein interactions (PPIs) are challenging targets for therapeutic design but scientists have, for decades, acknowledged the ease with which specific disruption of protein-protein complexes can be achieved using peptides. Proteinprotein interactions underpin most cellular functions so their modulation has immense therapeutic potential and small $\mathrm{G}$ proteins, as master regulators of the cellular communication network, are dependent on PPIs for every level of their functionality (Figure 1). Unlike the issues often encountered with small molecules, peptides are known for their exquisite selectivity, leading to fewer side effects, and consequently are relatively safe and welltolerated therapeutics. In general however, peptides do not readily traverse cell membranes, limiting their application against intracellular targets and even if they can be introduced into the cellular environment they are then susceptible to proteolytic attack. However the discovery and development of cell penetrating peptide sequences, together with the introduction of constraining technologies, has moved the field forward.

Stabilized peptides fall into the category of macrocycles, a well-known class of chemicals, whose use in therapeutics is well established. Macrocycles are defined by IUPAC as cyclic macromolecules or molecules having a cyclic portion containing at least 12 atoms. Therapeutic macrocycles include natural products, such as the antibiotics erythromycin and rifampicin, anti-tumour agents for example, actinomycin $\mathrm{D}$, the immunosuppressant 
cyclosporin $\mathrm{D}$ and the ubiquitous rapamycin and the rapalogues. Peptidic macrocycles include cyclic peptides containing both proteinogenic and non-ribosomal amino acid backbones [1]. Conventionally larger and far more complex than small molecules, they defy the chemical conventions accepted for therapeutic moieties while still possessing impressive levels of efficacy and more surprisingly, oral bioavailability [2].

Most currently available therapeutic macrocycles are either natural products or their derivatives. Although macrocycles possess many of the properties required in a drug they are often difficulty to design due to lack of structural information. Progress is often most forthcoming when the power of synthetic and medicinal chemistry approaches is directed towards naturally occurring starting molecules whose mode of action has been defined biophysically and structurally. More recently, there has been a shift in the macrocycles being developed away from natural products and towards those based on de novo scaffolds originating from structure-based design [2]. In the field of small $\mathrm{G}$ proteins we are privileged to have a wealth of structural data to drive engineering of such moieties, especially peptide macrocycles.

Macrocyclic peptides are typically 1-5 kDa, allowing them to establish larger binding interfaces with their targets than small molecule drugs and therefore to address destabilization of PPIs. Their constrained framework endows them with chemical stability but still allows for conformational flexibility to mediate induced fit on target binding, an important feature when considering targeting small G proteins. Small G proteins generally have two flexible regions, known as switch 1 and 2, which are sensitive to the bound nucleotide. The two switch regions mediate interactions with most upstream and downstream binding partners and so are likely to form at least part of the binding sites for orthosteric inhibitors.

The majority of constrained peptidomimetic approaches seek to trap the essential binding determinants of a protein within a short peptide that is then constrained and matured for cell penetrating properties. PPIs dominated by a short sequence in one of the interacting partners or a defined segment of one of the domains involved are suitable for inhibition by peptidomimetics. An analysis of secondary structural elements at protein-protein interfaces found that $\alpha$-helices were present in $62 \%$ of interfaces in protein complexes in the protein 
data bank [3], underpinning the interest in stabilizing $\alpha$-helical peptides as therapeutic PPI inhibitors. Two main approaches have been adopted for stabilizing $\alpha$-helical peptides: hydrocarbon staples and hydrogen bond surrogates, although several other methods also exist (see [4] for a review). In a hydrogen bond surrogate peptide, the hydrogen bond between the $\mathrm{CO}$ of residue $\mathrm{n}$ and the $\mathrm{NH}$ of residue $\mathrm{n}+4$ inside the $\alpha$-helix is replaced by a covalent bond. In hydrocarbon stapled peptides, the covalent bond is between sidechains (and therefore on the outside of the helix), and takes the form of an olefin group between residues $n$ and $n+4$, or $\mathrm{n}$ and $\mathrm{n}+7$. Other methods of helix stabilization include lactam and triazole bridges (reviewed in [5] and [6]). $\beta$-hairpins are also frequently identified in PPI interfaces indicating that these can, and indeed are, being exploited [7]. Furthermore, peptides with no defined secondary structure can also be used as templates, as cyclization methodologies, including end-to-end covalent linkage or disulphide bridges, can be employed to improve their properties. Efficacy of these peptides results from simple competitive inhibition of the PPI from which the peptide is derived.

Reports also suggest that in some case cyclization imbues peptides with favourable qualities such a membrane penetration, metabolic stability and better pharmacokinetics (reviewed in [8]). Whereas these properties may be attributable to the cyclization per se, in the case of peptide stapling, the staple itself seems to simultaneously aid cell penetration, facilitating attack of intracellular targets and increasing the efficacy of the modality. Currently the field has not evolved sufficiently to have well-defined rules for generic peptide design and stabilization, although there has been significant success in individual cases. Engineering of a constrained peptide with high target affinity, selectivity and metabolic stability would enhance our therapeutic repertoire not with another warhead or missile, but rather with a blockade. Unlike the toxic, small molecule drugs we often seek to deliver, these weapons, by virtue of their inherent properties, would neutralize cellular signals by blockading their transmission.

\section{Ras superfamily peptide and peptidomimetic inhibitors.}

\section{Targeting membrane localization}

The first peptides that targeted Ras family proteins were based on the discovery of the role of $\mathrm{C}$-terminal residues in directing the post-translational lipid modifications crucial for 
membrane association and therefore signalling. Ras superfamily proteins that are lipidated at their C-terminus include a CAAX consensus sequence, where Cys is the site of modification, $\mathrm{A}$ is an aliphatic amino acid and $\mathrm{X}$ directs the specificity towards farnesyl transferase (FTase) or geranylgeranyl transferase (GGTase). It was found that tetrapeptides based on the Cterminal sequences of H-Ras (CVLS), K-Ras (CIIM) or N-Ras (CVVM) were able to inhibit farnesylation of $\mathrm{H}$-Ras by purified farnesyltransferase [9]. Peptidomimetics designed using these sequences as a starting-point were hypothesized to be useful farnesyl transferase inhibitors (FTIs) with fewer side effects than farnesyl pyrophosphate-based moieties, which, it was assumed, would interfere with other processes such as steroid biosynthesis. Peptides that include or mimic the C-terminal Met or Ser would be selective for farnesyltransferase, since the related enzyme, geranylgeranyltransferase, recognizes sequences culminating in a Leu residue.

The CIIM sequence was used as a basis for peptide design: two of the three peptide bonds were reduced and the Met residue was replaced by homoserine lactone [10] to reduce hydrolysis and improve cell uptake by removing the negative charge at the C-terminus. These peptides were active, although the lactone compound was $\sim 10$-fold less potent than a peptide with a Ser residue at the C-terminus. The peptides inhibited Ras processing in NIH3T3 cells and reduced Ras-dependent transformation.

One problem with CIIM-based peptides was that they would themselves be farnesylated, which would reduce their affinity for the enzyme and render them less effective. A screen of 42 tetrapeptides, with varying amino acids at positions 2,3 and 4 , showed that an aromatic amino acid at position 3 produced better inhibitors [11] and that the best tetrapeptide, CVFM, was not itself a substrate for the enzyme [12]. CVFM, which had an $\mathrm{IC}_{50}$ of $\sim 40 \mathrm{nM}$, was used as a starting point for generation of more potent inhibitors. Again, the peptide bonds between $\mathrm{C}-\mathrm{V}$ and $\mathrm{V}-\mathrm{F}$ were reduced to improve the peptide resistance to proteases: this improved the $\mathrm{IC}_{50}$ for FTase 2-fold but also increased their ability to inhibit GGTase in vitro [13]. These peptides had only modest effects in cells, despite showing increased stability in cell lysates, presumably due to poor uptake.

In a different approach, the central two residues (VF) were replaced by a benzodiazepinebased scaffold, BZA [14] and the best of these, with a methylated N-terminus, was a more potent inhibitor when the C-terminus was esterified, likely due to improved cell uptake. This 
peptide also inhibited growth of Ras-transformed rat fibroblasts and murine myoblasts. A similar avenue led to the replacement of the central residues with 3-aminomethylbenzoic acid (AMBA), which was more potent than CIIM, CVIM and CVVM, but was not farnesylated itself [15].

Despite the promising results in vitro, and their ability to kill cancer cells in animal models, FTIs proved a major disappointment in halting Ras-driven cancers in the clinic (reviewed in [16]. One hurdle was that K-Ras and N-Ras proteins become geranylgeranylated in the presence of FTIs, bypassing the effects of the inhibitor. Similar principles allowed GGTIs to be developed, using tetrapeptides based on CXXL sequences as the basis for peptidomimetic design. The Cys at the N-terminus was replaced by methyl imidazole and the central dipeptide replaced by 3-aryl-piperazin-2-one derivatives. One peptidomimetic had an $\mathrm{IC}_{50}$ around $10 \mathrm{nM}$ for GGTase and was more than 5000-fold weaker for FTase. This molecule inhibited Ral proteins, which are geranylated, to bring about growth inhibition and apoptosis [17]. Although this suggested that combinations of GGTIs and FTIs could be a feasible approach, there are likely to be significant problems with toxicity using this approach (reviewed in [18]).

\section{Targeting exchange factor binding}

Lack of success with FTIs was a serious blow to the field: a significant effort had underpinned these campaigns and failure undermined confidence in both attacking Ras and the use of peptides as therapeutics. It was acknowledged that targeting small $\mathrm{G}$ proteins directly would be a difficult task and little progress was made for several years. In general, the rate-limiting step in $\mathrm{G}$ protein activation is their interaction with guanine nucleotide exchange factors (GEFs) and like many protein-protein interactions, these are notoriously difficult to target with small molecules. The astonishing progress in peptide chemistry, along with the vast amount of structural data that has become available over the last two decades however, suggested a solution to this problem.

\section{Inhibiting Ras via Sos-based peptides}

The structure of the complex formed between nucleotide-free Ras and Sos revealed the molecular basis for nucleotide exchange [19] and showed that the interface between the two 
proteins is extensive, burying 3,600 $\AA^{2}$. Although the interaction is mediated by a helical hairpin in the Sos protein, only one helix in the hairpin, $\alpha \mathrm{H}$, makes extensive contacts with Ras: the other plays a structural role. The Sos $\alpha \mathrm{H}$ helix inserts into the Ras structure, displacing switch 1 from the nucleotide binding site and stabilizing the nucleotide-free form of the Ras protein (Figure 2A). Specific interactions made by Sos include Leu938, which blocks the $\mathrm{Mg}^{2+}$-binding site, and Glu942, which displaces the $\alpha$-phosphate of GDP/GTP and forms a hydrogen bond with Ras Ser17 (Figure 2B). As well as these 'catalytic' interactions close to the nucleotide binding site, the Sos molecule also binds to switch 2, partially burying the switch 2 helix and generally ordering the conformation of the switch through a mixture of hydrophobic and polar interactions. Engineered molecules therefore, that mimic the interaction of Sos with Ras, but form a complex that is unable to complete nucleotide exchange, would be Ras inhibitors.

The importance of the interactions with Sos $\alpha \mathrm{H}$ was first exploited by the Arora and Bar-Sagi groups, who designed a series of inhibitory peptides based on this helix [20]. As this was a structure-based design, the authors first performed a computational alanine scan on the two available complex structures [21]. This simple step allows the prediction of hotspots [22] within a binding interface, quantifying the effects of Ala substitution as a change in the binding energy of a complex $(\Delta \Delta \mathrm{G})$, while accounting for any effects of the substitution on the stability of the free proteins. Even though this is only predictive, it is a useful undertaking in the design of peptides. A predicted $\Delta \Delta \mathrm{G}$ of more than $1 \mathrm{kcal} / \mathrm{mol}$ is taken to suggest that a particular residue is important for binding. For Sos binding to Ras, it allowed the authors to define the minimal helix for binding as Phe929-Asn944, since these residues both contributed significantly to the energy of the interface. Only two other residues within the helix had $\Delta \Delta \mathrm{G}$ values greater than $1 \mathrm{kcal} / \mathrm{mol}$ : Thr935 and Glu942. It is always interesting to compare the computational Ala scan with any experimental data available and the Bar-Sagi group had previously performed some mutational analysis based on their structure [23]. They assessed the binding of wild type and mutant proteins by Western blots with various Sos concentrations, yielding semi-quantitative binding data. The F929A mutation was disruptive for binding, in agreement with the in silico results. In contrast, T935A or a L938A/E942A double mutant only had a small effect on binding and did not inhibit the exchange activity of Sos. Hence, although Ala scanning can aid the peptide designer, experimental mutational data is still crucial for understanding thermodynamically important contributions at the interface. 
The first peptide produced was simply the sequence of Sos, residues 929-944 (Figure 2C) but this was not sufficiently soluble to be a useful inhibitor. Changes to the sequence were made with several goals in mind: improving the solubility, enhancing the helicity and improving the potency. Residues whose sidechains did not contact Ras and that were hydrophobic were obvious candidates for improving solubility by changing them to hydrophilic amino acids. With a judicious choice of residue combinations, helices can be stabilised by these changes. It is well known that some amino acid types have a higher propensity to be within $\alpha$-helices than others [24], so that for example, Ala, Arg and Leu are favourable, while Val, Thr and Gly are unfavourable, and Pro should be completely avoided because it is generally helix breaking. Layered on these considerations is the fact that sidechains of residues at positions $n$ and $n+3 / n+4$ are next to each other in space, so that if, for example, $n$ is negatively charged and $n+4$ is positive, they can form a salt-bridge, which stabilizes any helix formed [25]. This works for $n, n+3$ pairs as well, although it is less stabilizing. Both Arg and Lys are positively charged and have high helical propensities. There are also two negative amino acids, Glu and Asp, but Glu is much more favourable for helix formation. Patgiri et al. therefore generated Peptide 3, with Phe930 changed to Glu, Leu934 replaced by Arg and Asn936 replaced by Glu (Figure 2C). They also changed residues outside the binding region (Ile937, Thr940 and Gly943) to helix promoting residues (Leu, Ala, Ala respectively). One residue within the binding region, Thr935, was changed to Leu, on the basis that this residue is in a hydrophobic environment and that Leu is more helix stabilizing that Thr. It is interesting that this residue was identified by the Ala scan as one whose replacement would be detrimental to binding. Nevertheless, this single change increased the helicity and the inhibition of Sos-mediated nucleotide exchange.

The $\alpha$-helix in peptide 3 was then stabilized using the hydrogen-bond surrogate method to generate HBS3. The HBS was added between a 4-pentenoic acid positioned just before the essential Phe929 and Gly931. Addition of the HBS stabilized the $\alpha$-helix compared to the linear peptide (increasing helicity from $24 \%$ to $56 \%$ ), which was judged by circular dichroism (CD), although this was carried out in the presence of $10 \%$ trifluoroethanol, a wellknown helix-promoting agent [26]. HBS stabilization of the helix increased the exchange inhibition from $37 \%$ to $64 \%$, compared to the linear peptide. An HBS-stabilised control peptide was also produced, which had F929A/E942A/N944A mutations: these were the three 
remaining residues highlighted by the computational Ala scan. This peptide (called HBS7) had similar helicity to HBS3 but was a very poor Sos inhibitor due to its lower affinity for HRas. It is interesting that the HBS3 peptide bound to nucleotide-free H-Ras with a higher affinity (more than 5-fold) than to GDP-bound Ras. This suggests that the peptide should stabilise the nucleotide-free form of the Ras protein and therefore could actually enhance the exchange. The data presented showed that this was not the case and an explanation of this is not immediately obvious without structural data on the peptide-Ras complex.

Evidence that the peptides bound to the same region of the Ras protein as Sos was provided by their inhibition of the exchange and was validated using HSQC NMR experiments to map the binding interface of HBS3 on the Ras protein. This powerful technique allows mapping of residues involved in binding contacts, although it must be interpreted carefully. The NMR spectra report on the chemical environment of each NH in the Ras protein backbone. If binding of the peptide perturbs the environment around a particular residue, the position (chemical shift) of the peak corresponding to its NH will change: these changes can be quantified and mapped onto the structure of the protein. The caveat to these experiments is that if the peptide binding causes conformational changes in the protein, it will elicit false positives in the chemical shift mapping data. In small $\mathrm{G}$ proteins the switch regions are extremely susceptible to small structural changes and sample several different conformations in the absence of other binding partners. NMR spectra were recorded on the free, ${ }^{15} \mathrm{~N}$-labelled Ras protein, and again in the presence of the HBS3 peptide. The chemical shift changes in Ras were rather small, which is consistent with the affinity being relatively low. They did however map to a region that overlaps the Sos-binding site, and together with the inhibition of exchange observed the NMR data suggest that the peptides do indeed bind to the correct interface.

Peptides were generated with a fluorescein label so that their uptake into cells could be assessed. As is often the case, the HBS-stabilised peptides were visible within cells while the linear peptide was not. This could be due to differences in the efficiency of uptake but the susceptibility of the unconstrained peptides to proteolysis once inside the cell may also be a factor. Once inside HeLa cells, the ability of the peptides to inhibit Ras activation was measured by pulldown of immobilised effector proteins and by analysis of downstream signalling pathways. By both of these measures of Ras activation, the HBS3 peptide outperformed two control peptides. 
The HBS stabilized peptides, although useful as a proof of principle, were of rather low affinity. The Walensky group used the same helix, 929-944, and added a hydrocarbon staple to various positions without any other deviations from the Sos sequence [27]. Three peptides were tested with a stapled position on the back face of the Sos binding surface, 933-937 (SAH-SOS1A), 930-934 and 937-941; one control peptide was generated with the staple on the front surface, 932-936 (SAH-SOS1B). There were no CD data reported for these peptides so it is not possible to assess their overall helicity; however apart from the control peptide they all bound tightly to K-Ras and its oncogenic mutants with affinities of around $100 \mathrm{nM}$. This supports the use of peptide stapling, since this is a higher affinity than the binding of the entire Sos catalytic domain. Only the SAH-SOS1A tight-binding peptide was developed further, presumably because it was the most soluble. Both SAH-SOS1A and SAH-SOS1B peptides were modified by the addition of two Arg residues at their N-terminus (Figure 2C) to change their charge from -1 to +1 , since positively charged peptides are often more readily taken up into cells, and their binding checked again to ensure that this change did not modulate the affinity. Uptake into cells was confirmed, although there was variation in uptake efficiency in different cell types. The peptides inhibited K-Ras-Sos interactions in vitro, with similar affinities for the GDP- and GTP-loaded K-Ras proteins. Interestingly, the peptides reduced the melting temperature of both forms of $\mathrm{K}$-Ras by around $1{ }^{\circ} \mathrm{C}$, indicating that the $\mathrm{G}$ protein becomes more flexible. Consistent with this was the observation that the peptide inhibits association of either GDP or GTP, which implies that the nucleotide binding was reduced. Unlike the HBS-peptides described above, there is no data on the efficiency of inhibition of Sos-mediated exchange. NMR spectra of Ras in the absence and presence of peptides were recorded, to map the binding position of the peptides. Surprisingly, considering their binding affinities and the effects on nucleotide binding, the chemical shift changes observed in the presence of peptide were extremely small, with the exception of a patch next to switch 1 (27-29) and Arg149, which is adjacent to Ala146. The latter residue is involved in binding the guanine nucleotide base, contributing to the idea that the hydrocarbon stapled peptide modulates the nucleotide binding site. However, the lack of other chemical shift changes around this site argues against this. It is also clear that the HBS-stabilized peptides cause larger chemical shift changes that extend over more of the structure than the hydrocarbon stapled peptide. In particular, switch 2 residues are relatively unperturbed by the hydrocarbon stapled peptide but show large shift changes in the presence of the HBS peptide. This implies that the mode of binding of these peptides is rather different, which will only be 
resolved when high resolution structures are published. Despite these open questions, the hydrocarbon stapled peptides were cytotoxic towards cancer cells, with $\mathrm{IC}_{50}$ of 5-15 $\mu \mathrm{M}$ for $\mathrm{K}$-Ras mutant cancer cell lines and similar $\mathrm{IC}_{50}$ values for wt $\mathrm{K}$-Ras cancer cells. Control peptide did not kill the cells and neither did peptides with single residue changes that were unable to bind tightly to K-Ras. The cytotoxic peptides also inhibited Ras signalling pathways in the same cells, as judged by levels of phosphorylation of downstream targets. These results were translated into an in vivo context by using D. melanogaster expressing V12 mutant Ras. The stapled peptide was added to food and Ras signalling was inhibited, although a $100 \mu \mathrm{M}$ dose was required to see a robust effect on phospho-ERK and phosphoAKT levels.

\section{Screening approaches to inhibit Ras-Sos interactions}

An alternative approach was undertaken by a group at Takeda, who, rather than designing peptides, used phage display to screen for sequences that bound to immobilized G12D K-Ras protein [28]. To achieve selective binding to this mutant, free wt K-Ras was present during the selection to deplete the available library of peptides capable of binding to wt K-Ras. Three clusters of sequences were identified that bound selectively to G12D K-Ras and one of them, termed KRpep-2, bound to both GDP-bound and GTP-bound G12D K-Ras with similar affinity $\left(K_{\mathrm{d}} 50 \mathrm{nM}\right)$. There was some selectivity in Ras variants, since the binding to wt Ras and G12C was weaker. Maturation of the peptide was performed and yielded an indentical sequence but with two extra Arg residues at each end: this peptide was called KRpep-2d (Figure 3D). Both the original and matured peptides inhibited Sos-catalysed exchange of GDP for GTP, again with selectivity of G12D over both wt and G12C K-Ras. The matured KRpep-2d peptide bound with higher ( $9 \mathrm{nM})$ affinity and inhibited ERK1/2 phosphorylation in G12D mutant (but not G12C mutant) K-Ras lung cancer cell lines [29]. Both peptides included two Cys residues in their sequence and the inhibitory activity was drastically curtailed in the presence of a reducing agent, indicating that the Cys sidechains formed a disulphide bond necessary to constrain the peptide into a structure competent for binding. A disulphide-bonded peptide would, however, have poor efficacy against an intracellular target. Various alkyl derivatives of the disulphide bridge were tested and the best of these was the smallest, where a single methylene group bridged the two sulphur atoms. 
The importance of other peptide residues was probed by Ala scanning (Figure 2D), efficacy being measured by Sos-mediated nucleotide exchange inhibition [30]. Deletion of the four Arg residues at each end reduced the $\mathrm{IC}_{50}$ for all K-Ras variants, suggesting that, as well as their likely enhancement of cell uptake, they contribute some of the binding energy. Their replacement with D-Arg was less detrimental however, implying that the more proteaseresistant D-enantiomer could be utilized in next generation peptides. The structure of KRpep$2 \mathrm{~d}$ in complex with GDP-bound K-Ras (Figure 3A) shows that the Arg sidechains do not directly contact K-Ras but instead play a structural role (Figure 3C), forming a hydrogen bond between the termini of the peptide [29]. This, along with the disulphide bond, allows the peptide to form a flat-bottomed loop that inserts between 2 helices of K-Ras: $\alpha 2$ (within the switch 2 region) and $\alpha 3$. A comparison with the structure of $\mathrm{H}-\mathrm{R}$ as bound to Sos shows that the KRpep-2 peptide binds at a site distal to the Sos catalytic helix contact site (compare Figure 2A and Figure 3A). Therefore the observed inhibition of exchange activity by these peptides may be due to an allosteric rather than orthosteric effect. Hydrophobic sidechains in the peptide are bound within a pocket involving switch 2 (Figure 3C), which is also utilised for binding small molecule inhibitors that are covalently linked to K-Ras G12C mutants [31] (Figure 3B). However, the peptide causes structural rearrangements of the switch 2 helix $(\alpha 2)$, increasing the width of the binding pocket to accommodate the cyclic peptide. Presumably this locks switch 2 into a conformation that is incompatible with Sos binding. This study highlights the fact that Ras proteins are highly dynamic, particularly around their switch regions. Hence, designed inhibitory molecules may bind and allosterically modulate the Ras protein in unexpected ways.

\section{Targeting RhoGEF proteins: inhibition of RhoA activation}

Many of the Rho family GEFs are oncogenes in their own right (reviewed in [32]), so they represent potential targets for several cancers. Furthermore, lessons learned in these related systems could be applied to Ras inhibition. One early approach utilised peptide aptamers to screen for inhibitors for the Rho-GEF Trio [33]. Trio includes two pairs of tandem DH-PH domains, the second of which (TrioGEFD2) acts as a RhoGEF for RhoA (Figure 4A). The TrioGEFD2 was used as bait in a yeast two-hybrid screen, where the preys comprised a library of 20 mer peptides fused into a scaffold, the bacterial thioredoxin protein. Of the three hits, only one, called TRIAP $\alpha$, bound to the catalytic DH domain itself, and the aptamer protein inhibited TrioGEFD2-mediated exchange of nucleotide on RhoA. Testing with other 
RhoGEF proteins showed that only Kalirin, which is closely related to Trio, was inhibited by the TRIAP $\alpha$ aptamer. A 42 mer peptide (TRIP $\alpha$ ) corresponding to the variable sequence in the aptamer was also an inhibitor of exchange. The TRIP $\alpha$ peptide was fused to GFP and expressed in COS cells, where it was shown to interact with the Trio protein in coimmunoprecipitation and cause a reduction in the levels of active RhoA. Furthermore, expression of TrioGEFD2 reduced neurite outgrowth in neuronal cell lines and this effect was inhibited by expression of GFP-peptide.

The same group went on to mature the same peptide to target a splice variant of Trio, called Tgat, which was identified in adult $\mathrm{T}$ cell leukaemia patients. The Tgat protein only contains the DH2 domain with a short, 15 residue, C-terminal extension and requires its RhoGEF activity for transformation in focus-forming assays [34]. The original TRIP $\alpha$ sequence was used as a GST fusion protein but was not able to inhibit Tgat in a RhoA exchange assay. The TRIP peptide was matured by random mutagenesis of peptide sequences in a yeast twohybrid assay, where TrioGEFD2 was used as the bait, since Tgat is too toxic in yeast. This led to optimised peptides that inhibited both Tgat and the Trio DH2 domain, with $K_{\mathrm{i}}$ in the low $\mu \mathrm{M}$ range, and one of them inhibited RhoA activation in Tgat-transfected cell lines. This same peptide also inhibited transformation by Tgat (in a focus-forming assay) and formation of subcutaneous tumours in nude mice.

In all cases, the peptides used were displayed on a scaffold: they were purified as GST fusions for direct binding assays and transfected as GFP fusions for cell-based assays. This obviates the need for peptide synthesis and circumvents problems with cell uptake that can exist for linear peptides. It is clear however, that cell permeability could be a problem for peptide aptamers. It is also notable that the TRIP peptides contain four Cys residues, which could form disulphide bonds in vitro to stabilise the structures. If reducing agents attenuate the exchange inhibition, the disulphide bridges could be replaced with alternative covalent staples, which can aid cell uptake.

There is no mapping data to show where the TRIP $\alpha$ peptides bind to Trio, but their inhibition of exchange implies that they bind at or near the site occupied by RhoA. The Trio DH2-PH2 structure with RhoA shows that RhoA switch 1 and switch 2 are both involved in contacting the exchange factor (Figure 4A). When the PH2 domain is removed, in the Tgat splice variant, 
the TRIP $\alpha$ no longer inhibits the exchange activity, implying that the PH2 domain makes favourable interactions with peptide. Switch 2 is next to the PH2 domain in the complex structure (Figure 4B) and makes more extensive contacts with the DH2, suggesting that the TRIP $\alpha$ peptides may bind the DH2-PH2 on the same surface as switch 2. There is no obvious homology between the sequence of the peptide and switch 2 (Figure 4C) so the mode of binding cannot be easily predicted.

\section{Targeting RhoGEF proteins: inhibition of Rac1-DOCK2 interactions}

A phage display approach was used again by the Takeda group to find inhibitors for interactions between the small G protein Rac1 and the exchange factor DOCK2, which are a target for transplant rejection and some inflammatory diseases (reviewed in [35]). Rac1 is expressed widely and is one of three related isoforms suggesting that its inhibition is not a suitable avenue to explore. The DOCK2 protein is only expressed in haemoatopoietic cells and could represent a good target. The first inhibitor of DOCK2 was a small molecule, which had an $\mathrm{IC}_{50}$ around $20 \mu \mathrm{M}$ but cross-reacted with other DOCK proteins [36]. It was reasoned that peptides, being larger, would have a better chance of high selectivity for just the DOCK2 protein. The screen was performed with the DOCK2 Rac-binding region as bait. The bound phages were then eluted with Rac1 to identify those displaying peptides that competed with DOCK2-Rac1 interactions [28]. Cyclic peptides were again found to be the most efficient inhibitors of DOCK2-mediated Rac1 exchange (Figure 4F) and these were matured by addition of Arg residues to the termini to improve cell uptake and stabilization of the disulphide bond by addition of o-xylene. These changes resulted in a peptide that bound to DOCK2 with a low nM affinity and which inhibited Rac1 exchange by DOCK2 but did not inhibit the closely related exchange factor DOCK1.

Peptide uptake was assessed using an elegant assay for cytoplasmic location of peptide: a luciferin moiety is attached via a disulphide bond to the peptide and is only released when it meets the reducing conditions of the cytoplasm. This means that peptide within endosomes or adsorbed on the outside of the membrane is effectively invisible, while peptide within the cytoplasm can be detected semi-quantitatively in cells transfected with luciferase. The matured peptide showed the most robust uptake and activity in a cell migration assay. The same luciferin assay was also used to assess the efficiency of 13 cell penetrating peptides (CPPs) in delivering the first generation of DOCK2-inhibitory peptides as well as testing 
novel CPPs based on influenza viral protein PB1-F2 [37]. A thorough investigation of cell uptake, cell viability and correlation between in vitro binding of the modified peptides with inhibition of cell migration, allowed the optimum cell penetrating sequence to be selected, which in this case was the novel CPP.

The mode of binding of the DOCK2 inhibitory peptides is not known, but the structure of the DOCK2-Rac1 complex shows that the exchange factor makes most of its contacts with Rac1 switch 1 (Figure 4D, E). This suggests that the peptide could interact with DOCK2 and compete with switch 1 binding. Comparison of the sequence of the optimised peptide with switch 1 reveals that there is partial similarity, particularly in the placement of the aromatic sidechains (Figure 4F) and that switch 1 forms a loop that could be mimicked by a cyclic peptide.

\section{Targeting effector protein binding}

An alternative to inhibiting exchange factor interactions lies in disrupting interactions with effectors directly. This has the advantage that only active, GTP-bound Ras family proteins will be targeted. If the active form of the protein is the causative agent in disease, any inhibitor should therefore have fewer side effects than a non-nucleotide selective therapy.

\section{Macrocycle inhibitors of Ras}

Initial work on finding macrocycles to directly bind to Ras and prevent it from interacting with its effector proteins was undertaken in the Pei group. Screening a one-bead twocomponent naïve library of 4-6 cyclized residues composed of proteinogenic, D-amino acids and unnatural amino acids ultimately produced a macrocycle that bound to K-Ras G12V with an affinity of $830 \mathrm{nM}$ and prevented K-Ras interacting with Raf, RalGEF and Tiam1. Despite favourable biophysical attributes, the macrocycle showed no cellular activity, presumably due to a lack of membrane penetrating properties [38], but did indicate the tractability of directly targeting Ras with peptide macrocycles. This peptide was taken forward to incorporate cell penetrating properties, facilitated by the observation that it contained a sequence (Arg-Arg-(D- $\beta$-naphthylalanine)-Arg-(L-4-fluorophenylalanine)) with similarities to a recently identified CPP. In a rational design programme, the group screened a second- 
generation combinatorial peptide library that retained the cell-penetrating motif and screened for K-Ras binding ability. Screening, followed by SAR analysis and further engineering, resulted in a macrocycle with $120 \mathrm{nM}$ affinity for K-Ras and cell permeating properties. This peptide, termed Cyclorasin 9A5, inhibits Ras signalling pathways and cell growth and increases apoptotic cell death (Figure 5A). This work has demonstrated the possibility of combining PPI targeting with cell penetration to produce early stage inhibitors through a combination of screening and rational design [39].

The same group went on to screen a naïve bicyclic peptide library against K-Ras G12V. Again, low micromolar binding bicyclic peptides were identified but with poor cell penetrating properties [40]. This work however was extended to combine membrane penetration properties and Ras binding affinity into one bicyclic molecule, compartmentalising the properties into the two discrete cyclic portions of the macrocycle (Figure 5B). All bicyclic peptides appeared to enter cells and at that level the use of bicyclic peptides with a cell penetrating lobe seems to have utility. The selected peptides however were again only very weak inhibitors of Ras activity in cells [41]. However this method of imbuing benign cell penetrating properties onto a macrocycle could have future utility when employed with more powerful selection strategies for Ras binding peptides.

\section{Stapled peptide inhibitors of Ral small G proteins- effector interactions}

The Ras proteins themselves do not bind to any effector proteins via predominantly $\alpha$-helical interactions, rather they generally utilize an intermolecular $\beta$-sheet (reviewed in [42]. This has made the Ras proteins recalcitrant to stapled $\alpha$-helical peptide strategies for inhibition of effector binding. Another means of targeting Ras lies, however, in switching off specific effector pathways and indeed these approaches may prove to be less toxic. The major effector pathways downstream of Ras include the MAP kinase pathway, driven by active Raf proteins, and the PI3 kinase pathway. Both of these pathways are governed by enzymes and have been amenable to inhibition by small molecules. In the clinic, single effector inhibitors have not been as effective as hoped, although their use in combination therapies seems to be more promising (reviewed in [43]). The third well-characterised pathway driven by oncogenic Ras in cancer is the activation of RalGEFs, which cause the activation of another pair of small $\mathrm{G}$ proteins, RalA and RalB (reviewed in [44]). 
The rationale for using an effector protein as a template for the design is that the resulting peptides will target active, GTP-bound Ral proteins, the same form that is present in oncogenic Ras-driven cancers. Ral itself is rarely mutated in cancer, so there would be no allele-specific effects to contend with for these inhibitors. Unlike Ras, the Ral proteins bind to a structurally diverse group of effectors but the structures of three effectors have been solved in complex with Ral and all of them contact the same surface of the Ral protein. Therefore a peptide based on one of these effectors should inhibit the binding of all effectors and prevent active Ral from signalling. One of these effectors, RLIP76 (or RalBP1) utilises a coiled-coil motif to bind to Ral [45] and analysis of the binding interface showed that $80 \%$ of the surface area was contributed by the C-terminal $\alpha$-helix in the RLIP76 coiled-coil (Figure $6 \mathrm{~A})$.

Knowledge of the RLIP76-RalB complex structure was used to design peptides that inhibited Ral-effector interactions [46]. Firstly, peptides corresponding to the two helices were synthesized separately: one peptide comprised part of the first $\alpha$-helix and the loop between the helices, while the second corresponded to the entire $\mathrm{C}$-terminal $\alpha$-helix. Together these peptides encompassed all of the binding determinants in the RLIP76 coiled-coil. Binding analyses showed that only the peptide corresponding to the C-terminal $\alpha$-helix bound to active Ral proteins, albeit with an affinity more than 10-fold lower than that of the intact coiled-coil. NMR was used to map the binding of this peptide and to confirm that it engaged the same binding surface on the RalB protein as the RLIP76 coiled-coil. Hydrocarbon stapling was then used to stabilize the peptide into an $\alpha$-helical conformation: most of the stapled peptides were more helical than the unstapled version (as judged by CD) and one, stapled near the N-terminus of the helix, bound to RalB with a similar affinity to that of the RLIP76 coiled-coil (Figure 6A). Importantly, the peptide was selective for active Ral, binding to GMPPNP-bound RalA but not RalA.GDP. The peptide bound competitively with effectors, since it was displaced by RLIP76. Sec5 could not fully displace the peptide, which can be rationalised by examination of the structures of Sec5 and RLIP76. Sec5 covers a smaller binding surface on the Ral protein than the peptide would, so that it is likely that even at high Sec5 concentrations the peptide would still retain some low affinity binding. Cell uptake into human cells was demonstrated for this peptide and also inhibition of the interaction between endogenous Sec5 and RalB. Finally, the peptide was shown to inhibit 
RalB specifically in an autophagosome assembly assay. Briefly, nutrient deprivation leads to autophagosome assembly in a pathway requiring RalB and this was inhibited robustly by the peptide.

Although the Ral-inhibitory peptide has all the necessary characteristics to be a useful tool for studying Ral signalling, its binding affinity is currently too low to be a useful therapeutic starting point. Work is underway on second and third generation peptides with improved properties.

\section{Peptides to target Rab-effector complexes.}

Stapled peptides based on effector proteins have also been generated to target the Rab GTPases, which regulate vesicle transport and have been implicated in a number of diseases including cancer [47]. The known structures of Rab complexes were analysed and those where an $\alpha$-helix made a significant interface with the $G$ protein were used as a basis for peptide design [48]. Nine peptides were generated: seven based on effector proteins, one on the Rabin8 exchange factor, and one on the Rab escort protein 1, which escorts Rabs to geranylgeranyl transferases for lipid modification. The native peptides had very low affinities for the seven nucleotide-bound Rab proteins tested but four of them bound with moderate $(\mu \mathrm{M})$ affinities to the nucleotide-free forms of the Rabs. Hydrocarbon staples were introduced into the four peptides, using a range of staple positions across each peptide. For some of the peptides there was no increase in helicity on stapling, although most of them still bound to the nucleotide-free Rab proteins. One of the peptides (StRIP1), derived from the Rab-interacting protein 1, R6IP1 (Figure 6B), bound to GMPPNP-bound Rab8a (and not to the GDP-bound form or to any other nucleotide-bound Rab proteins) with a $K_{\mathrm{d}}$ of $22 \mu \mathrm{M}$. The same peptide was shown to compete fully with a known effector, OCRL, for binding, suggesting that the peptide binds to the same interface as OCRL.

Further optimisation was then performed, since the StRIP3 peptide was susceptible to proteolytic degradation and its cell uptake was poor [49]. Ala and Arg scanning revealed only one position in the 17 mer peptide that tolerated mutations but substitution with $\alpha$-methylated amino acids reduced the proteolysis. The final best peptide contained a double hydrocarbon staple, to prevent proteolysis, combined with substitutions to hydrophobic amino acids at two positions to improve the affinity for Rab8a to $\sim 13 \mu \mathrm{M}$. The intolerance to Arg substitutions 
presented a problem for cell uptake, since the overall charge of this peptide was negative, and neutral or positively charged peptides are generally more likely to be taken into cells. The elegant solution to this was to replace some of the negatively charged Asp and Glu residues with their neutral counterparts, Asn and Gln. These changes were sufficient to allow cell uptake of one peptide (StRIP16, Figure 6B), which was localized to endomembranes along with Rab8a, unlike the control, cell-penetrating Tat ${ }_{49-57}$ peptide, which remained in the cytoplasm. Surprisingly, the second staple used in StRIP16, between residues 911 and 916, involves residues that contact the Rab protein (Figure 6B), implying that this staple may direct interact with the $\mathrm{G}$ protein. The predicted contacts are, however, based on the structure of Rab6A with R6IP1 and the detailed interactions with Rab8a may be subtly different. An alternative to double olefin metathesis stapling of the Rab-binding peptides was also undertaken. Here, the second olefin group was replaced with an alkyne at the same position: this improves the efficiency since there is less chance for side reactions [50]. The best of these bicyclic peptides contained nine carbon atoms in the alkyne crosslink and bound with a 6.6 $\mu \mathrm{M}$ affinity to Rab8a, although its cell uptake was not optimised.

The Rab11-family of interacting proteins (FIPs) was also used as a starting point for peptide design. The FIPs utilise a long $\alpha$-helix followed by a turn and a short $3_{10}$ helix to bind to the Rab11 and Rab25 proteins (reviewed in [42]). Peptides corresponding to the C-terminus of the long helix, along with the turn and $3_{10}$ helix, should be sufficient to mimic the binding surface, based on the Rab25-FIP2 structure (Figure 6C). Peptides were designed based on representative members of two classes of FIPs, FIP1 and FIP3, with a range of staple positions, and the best stapled peptides based on native FIP sequences bound more tightly to Rab11a than to Rab25 [51]. Further optimisation included replacing a methionine (which was susceptible to oxidation) with norleucine and addition of positively charged residues in positions away from the binding site to yield RFP14 (Figure 6C), which bound with nM affinity to Rab25 and Rab11a. All of the peptides reported included a Pro residue that forces the backbone to form the turn that separates the $\alpha$-helix from the $3_{10}$ helix in the FIP2 structure. CD analysis was also performed but as the percentage helicity was not reported, it is not clear whether the peptides formed this turn or the hydrocarbon staple induced formation of $\alpha$-helix throughout. RFP14 reduced the ability of Rab25 to immunoprecipitate FIP1 from cell lysates, indicating that it blocks effector interactions. The nucleotide 
dependence of peptide binding was not tested, so it is unknown whether it binds specifically to the GTP-bound form.

RFP14 was taken forward into functional assays in breast and ovarian cancer cell lines. In cell lines where Rab25 stable transfection led to increased proliferation or cell migration, the peptide inhibited these effects of Rab25 overexpression. Furthermore, in triple negative breast cancer cell lines, where Rab25 has a tumour suppressor effect, the peptide stimulated proliferation and increased the cell migration in a wound-healing assay. In the ovarian cancer cell lines, RNAseq analysis indicated that the peptide antagonised Rab25-dependent changes in gene expression.

Moving further downstream: targeting a Wiskott-Aldrich Syndrome family member. Stapled peptides have also been utilised to inhibit actin cytoskeleton rearrangements downstream of the Rho family member Rac1 mediated through WASF3 [52]. The WASF3 seems to be associated with invasion and metastasis and is regulated by interaction with several proteins including CYFIP1. The knockdown of CYFIP1 reduced invasion, suggesting that inhibiting the CYFIP1-WASF3 interaction could inhibit metastasis. Peptides were designed based on structures of CYFIP1 with the related WASF3 protein to mimic an $\alpha$-helix within WASF3. These peptides were used in cell-based assays but no binding affinities were measured. The peptides reduced cell motility and WASF3 activation in breast and prostate cancer cell lines and disrupted the binding of Rac1 and Rac2. The same group then targeted another interaction in the same complex with stapled peptides, and found similar inhibition of invasion [53].

\section{Targeting GAP binding}

It may seem counter-intuitive to target the binding of the GTPase activating proteins, since they switch off small G proteins, so inhibiting their action could therefore prolong the signal. However, the GAPs are similar to effectors, in that they bind selectively to the GTP-bound, active form of the G protein. The mode of action of RasGAPs and RhoGAPs is conserved, and involves a critical arginine residue from the GAP (the 'Arg finger'), which inserts into the active site to stabilize the transition state. The Arg residue is contained on an unstructured loop region of the GAP, which allows it to interdigitate into the active site. The bulk of the 
RasGAP and RhoGAP proteins, however, are comprised of $\alpha$-helices, one of which lies between the two switch regions (Figure 7A), so stapled $\alpha$-helical peptides based on this sequence could potentially be used to disrupt the interaction of Ras with other molecules. Such peptides would not orthosterically inhibit Raf binding to the active Ras protein, since the helix does not directly overlap with the Raf binding site (Figure 7B). Peptides could rather modulate the structure of the Ras switch regions and allosterically block Raf binding. Currently there are no Ras-inhibitory peptides based on GTPase activating proteins described in the literature but this may represent a useful avenue for the design of stapled peptides for those $\mathrm{G}$ proteins where there are no other helical interacting proteins.

\section{Cell penetration of peptides}

Two recent papers have reported attempts to understand the principles behind cell penetration, with the aim of improving the design process, utilizing large numbers of peptides and quantitative assays of uptake of fluorescent peptides. A screen of more than 200 peptides was performed by the Verdine group, which were unmodified, hydrocarbon stapled (i, i+4 or i, $\mathrm{i}+7$ ) or "stitched" by tandem i, i+4 and i+11 staples [54]. The individual peptide libraries were similar in terms of molecular weight, charge and hydrophobicity, so that differences could be attributed solely to the difference in stapling. Overall, the stapled peptides were taken up much more readily and the stitched peptides were even more efficient. The other characteristic that affected uptake was charge: peptides with a net negative charge were not readily taken into cells. For stapled peptides, those with a net positive charge showed more cell penetration if their charge was between +1 and +5 but a higher charge was less efficient. For stitched peptides a charge of +3 to +7 seemed to be optimal. Inhibition of cellular ATP generation showed that uptake of the well-studied CPPs Tat and polyArg was not energydependent, while uptake of penetratin and stapled peptides was lower in the ATP-depleted cells [54]. This suggests that stapled peptides enter cells via an active process but that at least some linear peptides use passive diffusion. Inhibition of various endocytic pathways showed that only loss of sulphated glycans on the cell surface had an effect on peptide uptake and this was supported by experiments using $\mathrm{CHO}$ cells that were proteoglycan deficient. The simplest explanation of these findings is that the positively charged peptides are able to bind to the negative sulphated glycans on the membrane surface, which assists their anchoring to the cell and facilitates uptake. 
The Walensky group have also performed a systematic analysis of peptide uptake, again using hydrocarbon stapled peptides and using a staple scan across a single peptide [55]. In contrast to the Verdine group, they found that neither percentage helicity nor charge had any correlation with uptake but that hydrophobicity was the most important factor. If the peptide is drawn as a helical wheel, staples at the edge of the interaction interface, which extend the hydrophobic surface of the peptide, are more likely to be taken up into cells. When repeated with a different peptide and a longer $(\mathrm{i}, \mathrm{i}+7)$ staple the outcome was the same, indicating that this result is a general one. Interestingly, a principal component analysis revealed that once a threshold of hydrophobicity had been reached, a helicity of $60-87 \%$ was favourable for uptake. A number of single point mutants in the helix were also tested, in the context of the peptide with the best staple position for cell uptake. Of the 20 peptides tested, no single property correlated with the uptake, although it was evident that none of the changes resulted in more cellular uptake than the starting point.

It is clear from this extensive analysis that peptide uptake does not simply depend on positive charge, since addition of negative charges was not always detrimental and indeed too much positive charge could lead to nonspecific cell lysis. Furthermore, addition of more hydrophobic sidechains is generally favourable for membrane uptake, but has to be balanced with the problems associated with poorly soluble peptides and likelihood that very hydrophobic moieties will form non-specific interactions.

A recent study with peptides that activated p53 showed that a fine balance exists between membrane disruption and efficient cell uptake [56]. A screen was performed with various lipid-based delivery systems to find the right conditions for serum stability and improved cell uptake. There was no 'one size fits all' lipid system, but such systems may prove invaluable for peptides where sequence constraints prevent cellular uptake (reviewed in [8]).

Oral bioavailability is another unresolved issue when it comes to peptide-based drugs. A recent analysis of 125 cyclic peptides that are orally absorbed suggest that there are no general rules when it comes to peptide absorption in the gut [57], although replacement of backbone amides and increased rigidity seemed to be favourable. Obviously, such modifications may be incompatible with target binding, and even once absorbed, metabolism in the gut, liver or blood can reduce bioavailability. Native peptides can be modified in 
various ways, for example by replacement of backbone atoms to improve protease resistance and replacement of residues with unnatural amino acids (reviewed in [8]).

\section{Future prospects}

Recent work using protein-based scaffolds suggests other ways to target Ras beyond design based on known binding partners. One approach used a DARPin (Designed Ankyrin Repeat Protein) scaffold to generate a protein that bound preferentially to the GDP bound form of Ras with a high affinity and inhibited nucleotide exchange [58]. A scaffold from a thermophilic archaeon was used to generate (by yeast display) a protein that bound preferentially to the K-Ras G12D oncogenic mutant [59]. Monobodies based on the fibronectin type III domain were selected using a combinatorial library approach [60] and bound to Ras with nM affinity and inhibited Ras signalling. Surprisingly, the structure of the monobody in complex with H-Ras showed that the binding site of the inhibitor did not overlap with the exchange factor or effector interaction sites but prevented Ras dimerisation and nanoclustering. This opens a new and unexpected avenue for inhibitor design. All of these examples illustrate the possibility of using different sequences to target Ras, which could potentially be mimicked by stabilised peptides or peptidomimetics.

Moving beyond Ras itself, analysis of all G protein-effector complexes has shown that a large number of the intermolecular interactions are mediated by coiled-coil effectors [42], many of which will be amenable to stapled $\alpha$-helical peptide design. Although only a few stapled peptides have been generated so far, the large amount of structural data available implies that these are the tip of the iceberg. One of the bottlenecks lies in the design of stapled peptides. Analysis of the structure allows the residues that interact with the binding partner to be identified but computational mutational scanning does not always agree with experimental data $[20,61]$. This may be a particular feature with small $\mathrm{G}$ proteins, where the dynamics of the switch regions allow rearrangements that compensate for amino acid changes. Improvements in computational techniques will be essential to speed up the design of stapled peptides: for example optimizing the staple position and sequence for maximum helicity, solubility and cell permeability. Some improvements have been made in this direction (see [62] for a review) but more work is needed to understand the overarching principles. This 
will be facilitated as more structures of stabilised peptides in complex with their targets are solved.

One stapled peptide against an intracellular target, an MDM2/MDMX inhibitor that leads to reactivation of p53 [63] is currently in clinical trials (ALRN-6924). Although no interim results have been released, suggesting no success so far, many others will be need to be trialled to assess the efficacy of this modality. The growing number of peptides entering clinical trials suggests that their future is bright and that a new era of Ras inhibition is almost upon us.

\section{Acknowledgements}

We are grateful to Dr Katherine Stott for help with ChemDraw. Work in the authors' laboratory is funded by MRC and BBSRC.

\section{References}

[1] D.J. Newman, G.M. Cragg, Bioactive Macrocycles from Nature, in: J. Levin (Ed.), Macrocycles Drug Discov., 2014: pp. 1-36. doi:10.1039/9781782623113-00001.

[2] F. Giordanetto, J. Kihlberg, Macrocyclic drugs and clinical candidates: What can medicinal chemists learn from their properties?, J. Med. Chem. 57 (2014) 278-295. doi:10.1021/jm400887j.

[3] A.L. Jochim, P.S. Arora, Systematic analysis of helical protein interfaces reveals targets for synthetic inhibitors, ACS Chem. Biol. 5 (2010) 919-923. doi:10.1021/cb1001747.

[4] R. Rezaei Araghi, A.E. Keating, Designing helical peptide inhibitors of protein-protein interactions, Curr Opin Struct Biol. 39 (2016) 27-38. doi:10.1016/j.sbi.2016.04.001.

[5] Y.H. Lau, P. de Andrade, Y. Wu, D.R. Spring, Peptide stapling techniques based on different macrocyclisation chemistries, Chem. Soc. Rev. 44 (2015) 91-102. doi:10.1039/C4CS00246F.

[6] D.P. Fairlie, A. Dantas de Araujo, Stapling peptides using cysteine crosslinking, Pept. Sci. 106 (2016) 843-852. doi:10.1002/bip.22877.

[7] D. Obrecht, E. Chevalier, K. Moehle, J.A. Robinson, $\beta$-Hairpin protein epitope mimetic technology in drug discovery, Drug Discov. Today. 9 (2012) e63-e69. 
doi:10.1016/j.ddtec.2011.07.006.

[8] C. Corbi-Verge, M. Garton, S. Nim, P.M. Kim, Strategies to Develop Inhibitors of Motif-Mediated Protein-Protein Interactions as Drug Leads, Annu. Rev. Pharmacol. Toxicol. 57 (2017) 39-60. doi:10.1146/annurev-pharmtox-010716-104805.

[9] Y. Reiss, J.L. Goldstein, M.C. Seabra, P.J. Casey, M.S. Brown, Inhibition of purified p21ras farnesyl:protein transferase by Cys-AAX tetrapeptides, Cell. 62 (1990) 81-88. doi:10.1016/0092-8674(90)90242-7.

[10] N.E. Kohl, S.D. Mosser, S.J. DeSolms, E.A. Giuliani, D.L. Pompliano, S.L. Graham, R.L. Smith, E.M. Scolnick, A. Oliff, J.B. Gibbs, Selective inhibition of ras -dependent transformation by a farnesyltransferase inhibitor, Science (80-. ). 260 (1993) 1934 1937. doi:10.1126/science. 8316833.

[11] Y. Reiss, S.J. Stradley, L.M. Gierasch, M.S. Brown, J.L. Goldstein, Sequence requirement for peptide recognition by rat brain $\mathrm{p} 21$ ras protein farnesyltransferase., Proc. Natl. Acad. Sci. U. S. A. 88 (1991) 732-736. doi:10.1073/pnas.88.3.732.

[12] J.L. Goldstein, M.S. Brown, S.J. Stradley, Y. Reiss, L.M. Gierasch, Nonfarnesylated tetrapeptide inhibitors of protein farnesyltransferase, J. Biol. Chem. 266 (1991) 15575-15578. http://www.jbc.org/content/266/24/15575.full.pdf (accessed July 3, 2017).

[13] A.M. Garcia, C. Rowell, K. Ackermann, J.J. Kowalczyk, M.D. Lewis, Peptidomimetic Inhibitors of Ras Farnesylation and Function in Whole Cells, J. Biol. Chem. 268 (1993) 18415-18418. http://www.jbc.org/content/268/25/18415.full.pdf (accessed July 3, 2017).

[14] G.L. James, J.L. Goldstein, M.S. Brown, T.E. Rawson, T.C. Somers, R.S. McDowell, C.W. Crowley, B.K. Lucas, a D. Levinson, J.C. Marsters, Benzodiazepine peptidomimetics: potent inhibitors of Ras fanesylation in animal cells., Science (80-. ). 260 (1993) 1937-1942. doi:10.1126/science.8316834.

[15] M. Nigam, C.M. Seong, Y. Qian, A.D. Hamilton, S.M. Sebti, Potent inhibition of human tumor p21ras farnesyltransferase by A1A2-lacking p21 ras CA1A2X peptidomimetics, J. Biol. Chem. 268 (1993) 20695-20698. http://www.jbc.org/content/268/28/20695.full.pdf (accessed July 3, 2017).

[16] N. Berndt, A.D. Hamilton, S.M. Sebti, Targeting protein prenylation for cancer therapy, Nat. Rev. Cancer. 11 (2011) 775-791. doi:10.1038/nrc3151.

[17] S.C. Falsetti, D. Wang, H. Peng, D. Carrico, A.D. Cox, C.J. Der, A.D. Hamilton, S.M. Sebti, Geranylgeranyltransferase I Inhibitors Target RalB To Inhibit Anchorage- 
Dependent Growth and Induce Apoptosis and RalA To Inhibit Anchorage-Independent Growth, Mol. Cell. Biol. 27 (2007) 8003-8014. doi:10.1128/MCB.00057-07.

[18] A.D. Cox, C.J. Der, M.R. Philips, Targeting RAS membrane association: Back to the future for anti-RAS drug discovery?, Clin. Cancer Res. 21 (2015) 1819-1827. doi:10.1158/1078-0432.CCR-14-3214.

[19] P.A. Boriack-Sjodin, S.M. Margarit, D. Bar-Sagi, J. Kuriyan, The structural basis of the activation of Ras by Sos, Nature. 394 (1998) 337-343. doi:10.1038/28548.

[20] A. Patgiri, K.K. Yadav, P.S. Arora, D. Bar-Sagi, An orthosteric inhibitor of the RasSos interaction, Nat. Chem. Biol. 7 (2011) 585-587. doi:10.1038/nCHeMBIO.612.

[21] T. Kortemme, D.E. Kim, D. Baker, Computational Alanine Scanning of ProteinProtein Interfaces, Sci. Signal. 2004 (2004) p12-p12. doi:10.1126/stke.2192004pl2.

[22] T. Clackson, J.A. Wells, A hot spot of binding energy in a hormone-receptor interface., Science (80-. ). 267 (1995) 383-386. doi:10.1126/science.7529940.

[23] B.E. Hall, S.S. Yang, P.A. Boriack-Sjodin, J. Kuriyan, D. Bar-Sagi, Structure-based Mutagenesis Reveals Distinct Functions for Ras Switch 1 and Switch 2 in Soscatalyzed Guanine Nucleotide Exchange, J. Biol. Chem. 276 (2001) 27629-27637. doi:10.1074/jbc.M101727200.

[24] A. Chakrabartty, T. Kortemme, R.L. Baldwin, Helix propensities of the amino acids measured in alanine-based peptides without helix-stabilizing side-chain interactions, Protein Sci. 3 (1994) 843-852. doi:10.1002/pro.5560030514.

[25] S. Marqusee, R.L. Baldwin, Helix stabilization by Glu-...Lys + salt bridges in short peptides of de novo design., Proc. Natl. Acad. Sci. 84 (1987) 8898-8902. doi:10.1073/pnas.84.24.8898.

[26] H.J. Dyson, M. Rance, R.A. Houghten, P.E. Wright, R.A. Lerner, Folding of Immunogenic Peptide Fragments of Proteins in Water Solution II. The Nascent Helix, J. Mol. Biol. 201 (1988) 201-217.

[27] E.S. Leshchiner, A. Parkhitko, G.H. Bird, J. Luccarelli, J.A. Bellairs, S. Escudero, K. Opoku-Nsiah, M. Godes, N. Perrimon, L.D. Walensky, Direct inhibition of oncogenic KRAS by hydrocarbon-stapled SOS1 helices., Proc. Natl. Acad. Sci. 112 (2015) 17611766. doi:10.1073/pnas.1413185112.

[28] K. Sakamoto, Y. Kamada, T. Sameshima, M. Yaguchi, A. Niida, S. Sasaki, M. Miwa, S. Ohkubo, J. ichi Sakamoto, M. Kamaura, N. Cho, A. Tani, K-Ras(G12D)-selective inhibitory peptides generated by random peptide $\mathrm{T} 7$ phage display technology, Biochem. Biophys. Res. Commun. 484 (2017) 605-611. 
doi:10.1016/j.bbrc.2017.01.147.

[29] S. Sogabe, Y. Kamada, M. Miwa, A. Niida, T. Sameshima, M. Kamaura, K. Yonemori, S. Sasaki, J. Sakamoto, K. Sakamoto, Crystal Structure of a Human K-Ras G12D Mutant in Complex with GDP and the Cyclic Inhibitory Peptide KRpep-2d, ACS Med. Chem. Lett. 8 (2017) 732-736. doi:10.1021/acsmedchemlett.7b00128.

[30] A. Niida, S. Sasaki, K. Yonemori, T. Sameshima, M. Yaguchi, T. Asami, K. Sakamoto, M. Kamaura, Investigation of the structural requirements of K-Ras(G12D) selective inhibitory peptide KRpep-2d using alanine scans and cysteine bridging, Bioorg. Med. Chem. Lett. 27 (2017) 2757-2761. doi:10.1016/j.bmcl.2017.04.063.

[31] J.M. Ostrem, U. Peters, M.L. Sos, J.A. Wells, K.M. Shokat, K-Ras(G12C) inhibitors allosterically control GTP affinity and effector interactions, Nature. 503 (2013) 548551. doi:10.1038/nature12796.

[32] D.R. Cook, K.L. Rossman, C.J. Der, Rho guanine nucleotide exchange factors: regulators of Rho GTPase activity in development and disease, Oncogene. 33 (2014) 4021-4035. doi:10.1038/onc.2013.362.

[33] S. Schmidt, S. Diriong, J. Mery, E. Fabbrizio, A. Debant, Identifcation of the first Rho-GEF inhibitor, TRIPa, which targets the RhoA-specific GEF domain of Trio, FEBS Lett. 523 (2002) 35-42.

[34] N. Bouquier, S. Fromont, J.C. Zeeh, C. Auziol, P. Larrousse, B. Robert, M. Zeghouf, J. Cherfils, A. Debant, S. Schmidt, Aptamer-Derived Peptides as Potent Inhibitors of the Oncogenic RhoGEF Tgat, Chem. Biol. 16 (2009) 391-400. doi:10.1016/j.chembiol.2009.02.006.

[35] X. Guo, S.-Y. Chen, Dedicator of Cytokinesis 2 in Cell Signaling Regulation and Disease Development, J. Cell. Physiol. 232 (2017) 1931-1940. doi:10.1002/jcp.25512.

[36] A. Nishikimi, T. Uruno, X. Duan, Q. Cao, Y. Okamura, T. Saitoh, N. Saito, S. Sakaoka, Y. Du, A. Suenaga, M. Kukimoto-Niino, K. Miyano, K. Gotoh, T. Okabe, F. Sanematsu, Y. Tanaka, H. Sumimoto, T. Honma, S. Yokoyama, T. Nagano, D. Kohda, M. Kanai, Y. Fukui, Blockade of inflammatory responses by a small-molecule inhibitor of the Rac activator DOCK2, Chem. Biol. 19 (2012) 488-497. doi:10.1016/j.chembiol.2012.03.008.

[37] Y. Adachi, K. Sakamoto, T. Umemoto, Y. Fukuda, A. Tani, T. Asami, Investigation on cellular uptake and pharmacodynamics of DOCK2-inhibitory peptides conjugated with cell-penetrating peptides, Bioorganic Med. Chem. 25 (2017) 2148-2155. doi:10.1016/j.bmc.2017.02.022. 
[38] X. Wu, P. Upadhyaya, M.A. Villalona-Calero, R. Briesewitz, D. Pei, Inhibition of Ras-effector interactions by cyclic peptides, Medchemcomm. 4 (2013) 378. http://xlink.rsc.org/?DOI=c2md20329d.

[39] P. Upadhyaya, Z. Qian, N.G. Selner, S.R. Clippinger, Z. Wu, R. Briesewitz, D. Pei, Inhibition of Ras Signaling by Blocking Ras - Effector Interactions with Cyclic Peptides ** Angewandte, Angew. Chemie (International Ed English). 54 (2015) 76027606. doi:10.1002/anie.201502763.

[40] P. Upadhyaya, Z. Qian, N.A.A. Habir, D. Pei, Direct Ras inhibitors identified from a structurally rigidified bicyclic peptide library, Tetrahedron. 70 (2014) 7714-7720. http:/eutils.ncbi.nlm.nih.gov/entrez/eutils/elink.fcgi?dbfrom=pubmed\&id=25284901 $\&$ retmode $=$ ref\&cmd $=$ prlinks.

[41] T.B. Trinh, P. Upadhyaya, Z. Qian, D. Pei, Discovery of a Direct Ras Inhibitor by Screening a Combinatorial Library of Cell-Permeable Bicyclic Peptides, Acs Comb. Sci. 18 (2016) 75-85. doi:10.1021/acscombsci.5b00164.

[42] H.R. Mott, D. Owen, Structures of Ras superfamily effector complexes: What have we learnt in two decades?, Crit. Rev. Biochem. Mol. Biol. 50 (2015) 85-133. doi:10.3109/10409238.2014.999191.

[43] B. Fang, RAS signaling and anti-RAS therapy: Lessons learned from genetically engineered mouse models, human cancer cells, and patient-related studies, Acta Biochim. Biophys. Sin. (Shanghai). 48 (2015) 27-38. doi:10.1093/abbs/gmv090.

[44] L.R. Gentry, T.D. Martin, D.J. Reiner, C.J. Der, Ral small GTPase signaling and oncogenesis: More than just 15 minutes of fame, Biochim. Biophys. Acta - Mol. Cell Res. 1843 (2014) 2976-2988. doi:10.1016/j.bbamcr.2014.09.004.

[45] R.B. Fenwick, L.J. Campbell, K. V Rajasekar, S. Prasannan, D. Nietlispach, J.H. Camonis, D. Owen, H.R. Mott, The RalB-RLIP76 complex reveals a novel mode of ral-effector interaction., Structure. 18 (2010) 985-995. doi:10.1016/j.str.2010.05.

[46] J.C. Thomas, J.M. Cooper, N.S. Clayton, C. Wang, M.A. White, C. Abell, D. Owen, H.R. Mott, Inhibition of Ral GTPases using a stapled peptide approach, J. Biol. Chem. 291 (2016) 18310-18325. doi:10.1074/jbc.M116.720243.

[47] X. Qin, J. Wang, X. Wang, F. Liu, B. Jiang, Y. Zhang, Targeting Rabs as a novel therapeutic strategy for cancer therapy, Drug Discov. Today. 22 (2017) 1139-1147. doi:10.1016/j.drudis.2017.03.012.

[48] J. Spiegel, P.M. Cromm, A. Itzen, R.S. Goody, T.N. Grossmann, H. Waldmann, Direct targeting of Rab-GTPase-effector interactions., Angew. Chemie (International Ed 
English). 53 (2014) 2498-2503.

http://onlinelibrary.wiley.com/doi/10.1002/anie.201308568/full.

[49] P.M. Cromm, J. Spiegel, P. Küchler, L. Dietrich, J. Kriegesmann, M. Wendt, R.S. Goody, H. Waldmann, T.N. Grossmann, Protease-Resistant and Cell-Permeable Double-Stapled Peptides Targeting the Rab8a GTPase, ACS Chem. Biol. 11 (2016) 2375-2382. doi:10.1021/acschembio.6b00386.

[50] P.M. Cromm, S. Schaubach, J. Spiegel, A. Fürstner, T.N. Grossmann, H. Waldmann, Orthogonal ring-closing alkyne and olefin metathesis for the synthesis of small GTPase-targeting bicyclic peptides, Nat. Commun. 7 (2016) 11300. doi:10.1038/ncomms11300.

[51] S. Mitra, J.E. Montgomery, M.J. Kolar, G. Li, K.J. Jeong, B. Peng, G.L. Verdine, G.B. Mills, R.E. Moellering, Stapled peptide inhibitors of RAB25 target context-specific phenotypes in cancer, Nat. Commun. 8 (2017) 660. doi:10.1038/s41467-017-00888-8.

[52] Y. Teng, A. Bahassan, D. Dong, L.E. Hanold, X. Ren, E.J. Kennedy, J.K. Cowell, Targeting the WASF3-CYFIP1 complex using stapled peptides suppresses cancer cell invasion, Cancer Res. 76 (2016) 965-973. doi:10.1158/0008-5472.CAN-15-1680.

[53] Y. Teng, H. Qin, A. Bahassan, N.G. Bendzunas, E.J. Kennedy, J.K. Cowell, The WASF3-NCKAP1-CYFIP1 Complex Is Essential for Breast Cancer Metastasis, Cancer Res. 76 (2016) 5133-5142. doi:10.1158/0008-5472.CAN-16-0562.

[54] Q. Chu, R.E. Moellering, G.J. Hilinski, Y.-W. Kim, T.N. Grossmann, J.T.-H. Yeh, G.L. Verdine, Towards understanding cell penetration by stapled peptides, Medchemcomm. 6 (2015) 111-119. http://xlink.rsc.org/?DOI=C4MD00131A.

[55] G.H. Bird, E. Mazzola, K. Opoku-Nsiah, M. a Lammert, M. Godes, D.S. Neuberg, L.D. Walensky, Biophysical determinants for cellular uptake of hydrocarbon-stapled peptide helices., Nat. Chem. Biol. 12 (2016) 845-852. doi:10.1038/nchembio.2153.

[56] D. Thean, J.S. Ebo, T. Luxton, X.C. Lee, T.Y. Yuen, F.J. Ferrer, C.W. Johannes, D.P. Lane, C.J. Brown, Enhancing specific disruption of intracellular protein complexes by hydrocarbon stapled peptides using lipid based delivery, Sci. Rep. 7 (2017) 1763. doi:10.1038/s41598-017-01712-5.

[57] D.S. Nielsen, N.E. Shepherd, W. Xu, A.J. Lucke, M.J. Stoermer, D.P. Fairlie, Orally Absorbed Cyclic Peptides, Chem. Rev. 117 (2017) 8094-8128. doi:10.1021/acs.chemrev.6b00838.

[58] S. Guillard, P. Kolasinska-Zwierz, J. Debreczeni, J. Breed, J. Zhang, N. Bery, R. Marwood, J. Tart, R. Overman, P. Stocki, B. Mistry, C. Phillips, T. Rabbitts, R. 
Jackson, R. Minter, Structural and functional characterization of a DARPin which inhibits Ras nucleotide exchange, Nat. Commun. 8 (2017) 16111.

doi:10.1038/ncomms 16111 .

[59] M.J. Kauke, M.W. Traxlmayr, J.A. Parker, J.D. Kiefer, R. Knihtila, J. McGee, G. Verdine, C. Mattos, K.D. Wittrup, An engineered protein antagonist of K-Ras/B-Raf interaction, Sci. Rep. 7 (2017) 5831. doi:10.1038/s41598-017-05889-7.

[60] R. Spencer-Smith, A. Koide, Y. Zhou, R.R. Eguchi, F. Sha, P. Gajwani, D. Santana, A. Gupta, M. Jacobs, E. Herrero-Garcia, J. Cobbert, H. Lavoie, M. Smith, T.

Rajakulendran, E. Dowdell, M. Nazir Okur, I. Dementieva, F. Sicheri, M. Therrien, J.F. Hancock, M. Ikura, S. Koide, J.P. O, M.N. Okur, I. Dementieva, F. Sicheri, M.

Therrien, J.F. Hancock, M. Ikura, S. Koide, J.P. O’Bryan, Inhibition of RAS function through targeting an allosteric regulatory site, Nat. Chem. Biol. 13 (2016) 62-68. doi:10.1038/nchembio.2231.

[61] G.J.N. Tetley, H.R. Mott, R.N. Cooley, D. Owen, A dock and coalesce mechanism driven by hydrophobic interactions governs Cdc42 binding with its effector protein ACK, J. Biol. Chem. 292 (2017) 11361-11373. doi:10.1074/jbc.M117.789883.

[62] Y.S. Tan, D.P. Lane, C.S. Verma, Stapled peptide design: principles and roles of computation, Drug Discov. Today. 21 (2016) 1642-1653. doi:10.1016/j.drudis.2016.06.012.

[63] Y.S. Chang, B. Graves, V. Guerlavais, C. Tovar, K. Packman, K.-H. To, K.A. Olson, K. Kesavan, P. Gangurde, A. Mukherjee, T. Baker, K. Darlak, C. Elkin, Z. Filipovic, F.Z. Qureshi, H. Cai, P. Berry, E. Feyfant, X.E. Shi, J. Horstick, D.A. Annis, A.M. Manning, N. Fotouhi, H. Nash, L.T. Vassilev, T.K. Sawyer, Stapled $\alpha$-helical peptide drug development: A potent dual inhibitor of MDM2 and MDMX for p53-dependent cancer therapy, Proc. Natl. Acad. Sci. 110 (2013) E3445-E3454. doi:10.1073/pnas.1303002110. 


\section{Figure Legends}

Figure 1.

An overview of Ras processing and the GTPase cycle, indicating steps that have been targeted by inhibitors. Newly synthesized Ras is lipid modified by farnseyl transferases and then further processed by proteolysis of the C-terminus and carboxymethylation. $\mathrm{H}-$ and $\mathrm{N}$ Ras are also palmitoylated. Ras proteins associate with membranes via these lipid modifications but can be extracted and shuttled between different membranes by phosphodiesterase $\delta$, which is analogous to the GDI proteins for Rho and Rab families. Activation of an exchange factor (GEF) leads to release of GDP via a nucleotide-free RasGEF intermediate. Once the Ras protein is GTP-bound, it binds to downstream effectors (e.g. the Raf kinases) and activates downstream signalling pathways, or binds to a GTPase activating protein (GAP), which stimulates the intrinsic GTP hydrolysis activity. Ras is shown in blue, with the nucleotide sensitive switch regions coloured orange (switch 1) and yellow (switch 2) and the C-terminal isoprenyl group is cyan. The steps that have been targeted by inhibitors are coloured orange.

Figure 2.

Structure and peptide-based inhibition of the Ras-Sos complex.

A. The structure of Sos (green) in complex with nucleotide-free Ras (blue). One of the helices in Sos ( $\alpha \mathrm{H}$, shown in red) makes extensive contacts with Ras.

B. A close-up of the Sos $\alpha \mathrm{H}$ helix showing amino acid sidechains that point towards Ras (green) and the location of the two sidechains that were selected for hydrophobic stapling (red).

C. Sequences of Sos and Sos-based peptides designed to bind to Ras. Computational alanine scanning suggested that residues 929-944 were sufficient to bind to Ras and residues marked with a red star are those that were predicted to contribute most strongly to binding. The wild-type Sos peptide sequence was modified to improve both solubility and helicity, resulting in peptide 3. Changes were introduced to allow the formation of favourable salt bridges (blue dashed lines) between residues in adjacent turns of the helix. Residues whose sidechains are branched at the $\beta$-position or that are Gly in the WT sequence were also changed to Leu or Ala, which are helix inducing (coloured red). The addition of 4-pentenoic acid at the $\mathrm{N}$-terminus and 
modification of Gly931 allowed formation of a hydrogen bond surrogate link in HBS3, which increased the helicity further and improve the efficacy in exchange inhibition assays. The hydrocarbon stapled peptides were based on the WT Sos $\alpha \mathrm{H}$ sequence with the addition of two Arg residues at the $\mathrm{N}$-terminus to improve cell uptake. SAH-SOS1A has Tyr933 and Ile937 replaced with unnatural amino acids, which have 5 carbons terminating in an olefin group (S5) and will form an allhydrocarbon staple (grey). SAH-SOS1B is a negative control, with the staple designed to disrupt the Ras-binding interface.

Figure 3.

Phage display generated peptides to inhibit K-Ras.

A. The disulphide bonded peptide KRpep-2d (red) in complex with the K-Ras G12D mutant. Ras is coloured blue, with switch 1 coloured orange and switch coloured yellow. The nucleotide is shown in stick representation with carbons in cyan and the disulphide bond in KRpep-2d is coloured black.

B. The structure of a small molecule inhibitor (compound 6) covalently bound to K-Ras G12C. KRpep-2d and compound 6 bind to overlapping sites on K-Ras, at a region defined as an allosteric pocket. The inhibitor is shown in stick representation with the carbons in magenta and the disulphide bond to Ras Cys12 is shown in yellow. The orientation of panels A and B are the same as in Figure 2A, to illustrate that the binding site is distinct from the region bound by the Sos helix $\alpha \mathrm{H}$.

C. A close up view of KRpep-2d binding to K-Ras. The sidechains in the flat-bottomed loop that point towards K-Ras are depicted as green sticks. The Arg residues at each end of the peptide are coloured cyan.

D. The sequence of KRpep-2d. The red stars denote residues that were shown by experimental alanine scanning to be important for selective inhibition against G12D mutant K-Ras. Residues coloured pink are those which, when mutated to Ala, reduce the binding affinities to K-Ras WT and G12D/G12C mutants significantly.

Figure 4.

Peptide inhibitors of Rho family exchange factors. 
A. A model of Trio in complex with RhoA (based on the Trio-Rac1 structure). RhoA is blue, with switch 1 in orange and switch 2 in yellow. The Trio DH domain is green and the $\mathrm{PH}$ domain is grey.

B. Close up view of the RhoA switch 2-Trio interactions, showing the sidechains of the switch 2 residues that point towards Trio. It is clear that switch 2 makes more extensive contacts with the $\mathrm{DH}$ domain and is closer to the $\mathrm{PH}$ domain (shown as a semi-transparent grey surface).

C. The sequence of the TRIP $\alpha$ peptide that inhibits RhoA activation by the DH-PH pair but not by Tgat, which is missing the $\mathrm{PH}$ domain. Underneath is the sequence of RhoA switch 1, with the residues that contact Trio coloured orange. The peptide sequence is relatively long and has no obvious homology to switch 2 .

D. Structure of the complex formed between DOCK2 and nucleotide free Rac1. Rac1 is blue, switch 1 is coloured orange and switch 2 is yellow. DOCK2 is coloured green.

E. Close up view of the Rac1 switch 1-DOCK2 interactions showing the sidechains of switch 1 residues that point towards DOCK2. This region of switch 1 forms a loop that could be mimicked by a cyclic peptide.

F. The sequence of the DOCK2 inhibitory peptide. The sequence of switch 1 that forms intimate contacts with DOCK2 is shown underneath the peptide sequence with the residues that contact Rac1 coloured orange. Some conservation of the aromatic residues suggests that if the peptide and Rac1 bind orthosterically to DOCK2, the peptide could form at least some of these contacts.

Figure 5.

Macrocycles targeting Ras.

A. Cyclorasin 9A5.

B. Bicyclic Peptide 49 with its CPP and Ras targeting rings.

Figure 6.

Stapled peptides designed to inhibit effector interactions.

In panels $\mathrm{A}-\mathrm{C}$, the $\mathrm{G}$ protein is coloured blue, with switch 1 in orange and switch 2 in yellow. The effectors are coloured in pale pink, with the helix that is mimicked by a stapled peptide coloured red. Underneath each complex structure is a representation of the helix, with sidechains that contact the $\mathrm{G}$ protein shown as a stick representation. The sequence of each 
helix is shown underneath, with the $\mathrm{G}$ protein-contacting residues indicted by a red asterisk. The residues that were used in staple scans are coloured green and the location of the optimal staple is shown as a grey brace.

A. The structure of RalB in complex with RLIP76 used to design inhibitors with a hydrocarbon staple.

B. Rab6a in complex with R6IP1. Peptides based on R6IP1 inhibited Rab8a, rather than Rab6a but the overall R6IP1 binding site is presumably the same. The StRIP3 peptide was the best staple position in the context of the wild-type sequence of R6IP1, while StRIP16 was optimised for stability and cell uptake.

C. Rab25 in complex with FIP2. In this structure, two FIP2 coils are bound to two Rab25 molecules. The sequences of both FIP1 and FIP3 are shown below and the optimised peptide, RFP14, that showed good selectivity for Rab25 over Rab11a and improved cell uptake.

Figure 7.

RasGAP utilises an $\alpha$-helix to contact the Ras switches, which could be used to design stapled peptides.

A. The Ras-RasGAP complex shows that one $\alpha$-helix (coloured red) contacts H-Ras at both switch 1 and switch 2 . The catalytic 'Arg finger' comes from a different region of the RhoGAP protein. Ras is coloured blue, with switch 1 coloured orange and switch 2 coloured yellow. RasGAP is cyan.

B. The Ras-Raf complex shows that the binding site for Raf would not overlap with the RasGAP helix, but the orientation of the two switch regions in the Raf complex is likely to be incompatible with the binding of the GAP helical peptide. 


\section{Figure 1}

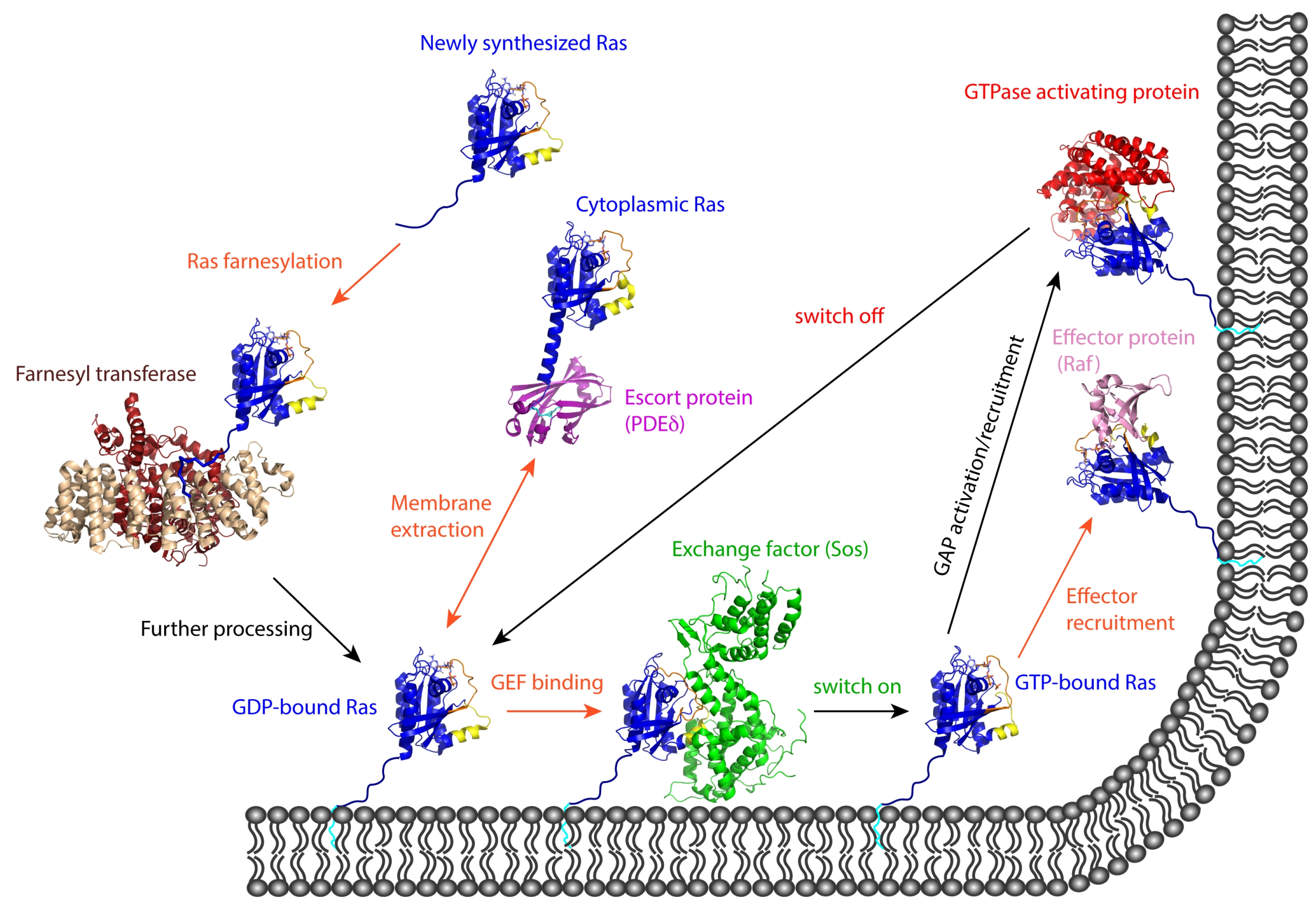




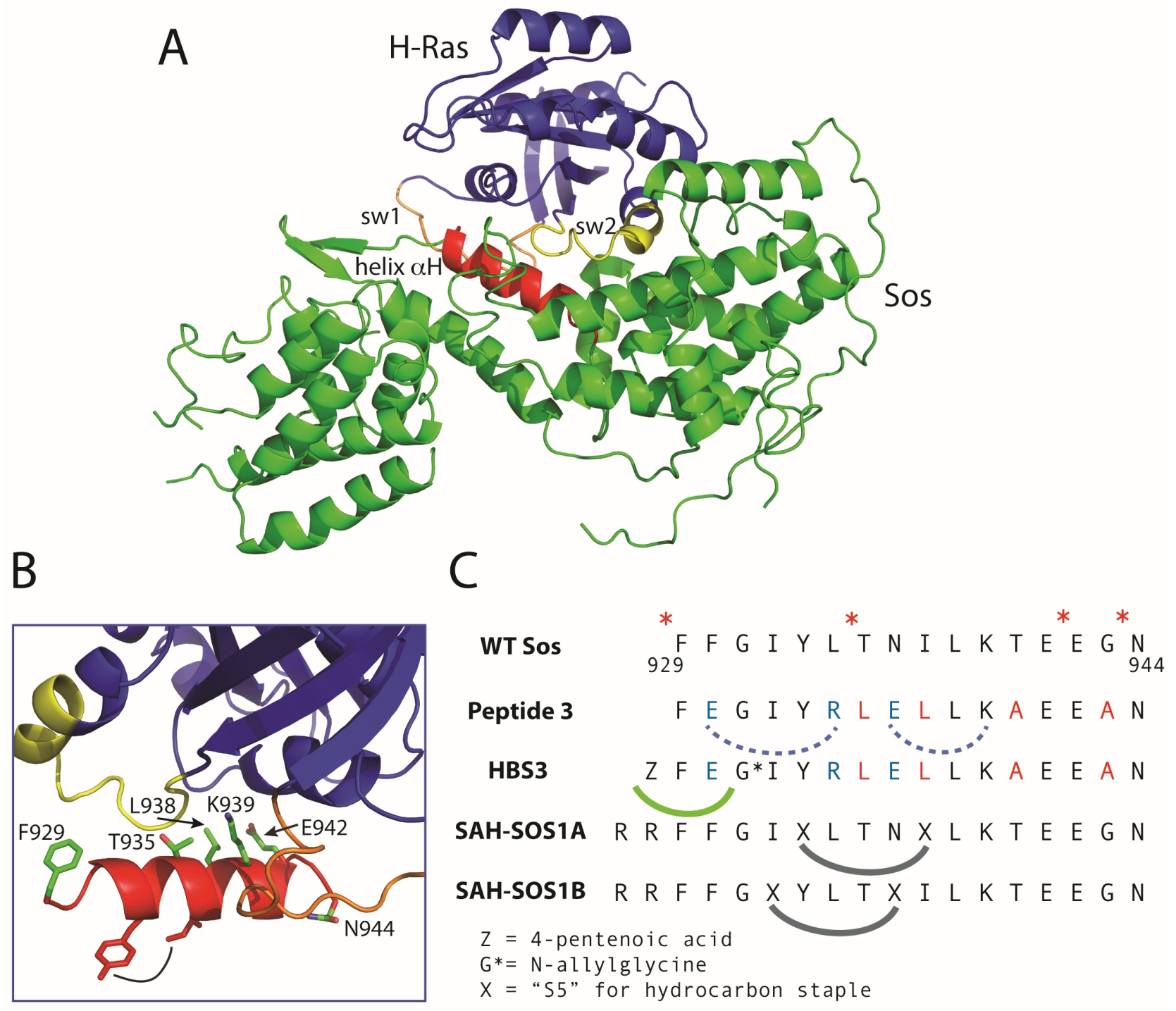

Figure 2 

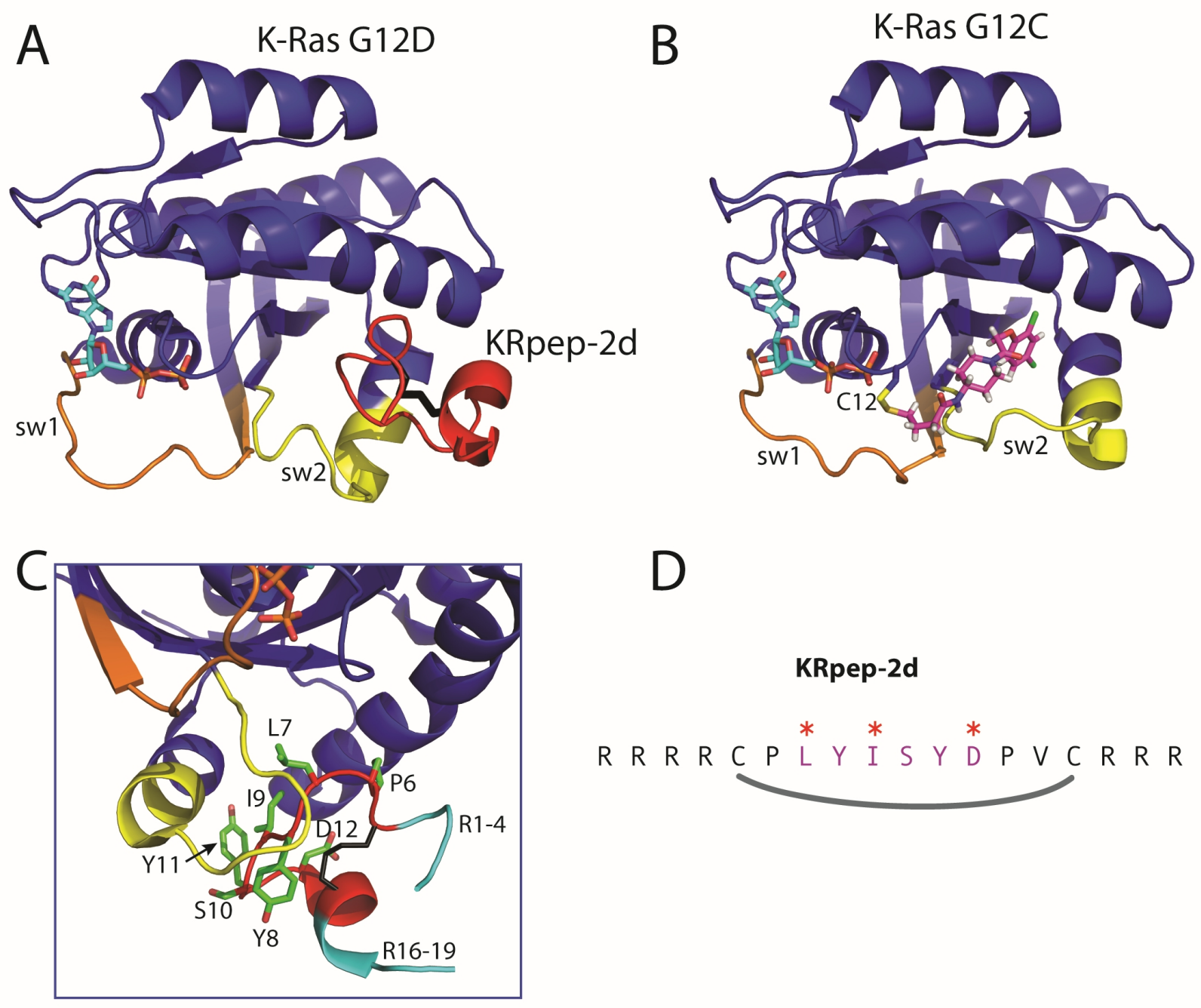

D

\section{KRpep-2d}

R R R R C P L L Y I S Y ${ }^{*} \mathrm{P}$ P C R R R R

Figure 3 


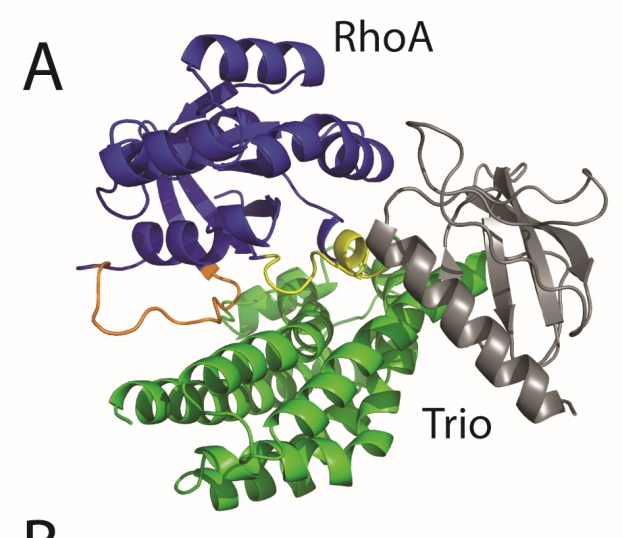

B

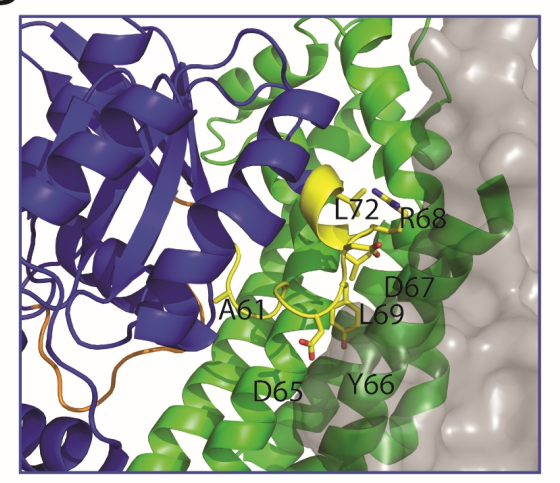

C TRIP $\alpha$

ICGYNLATLVMLGPSERVFCPLCEPCSS

RhoA switch 2

${ }_{60}$ TAGQEDYDRLRP $_{72}$

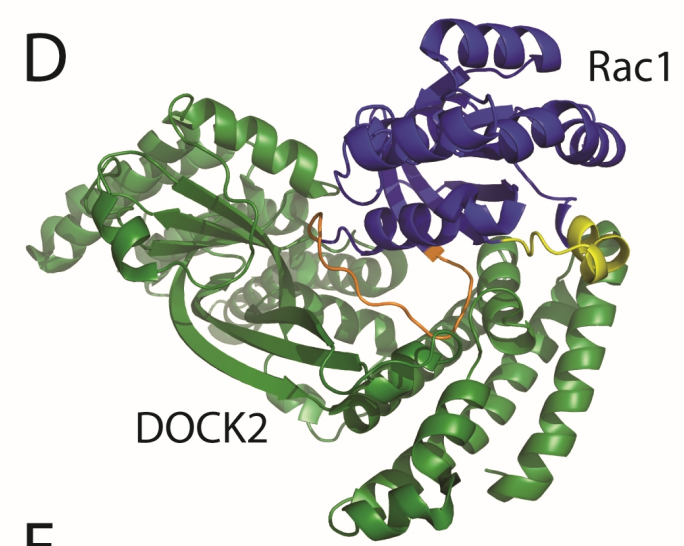

E

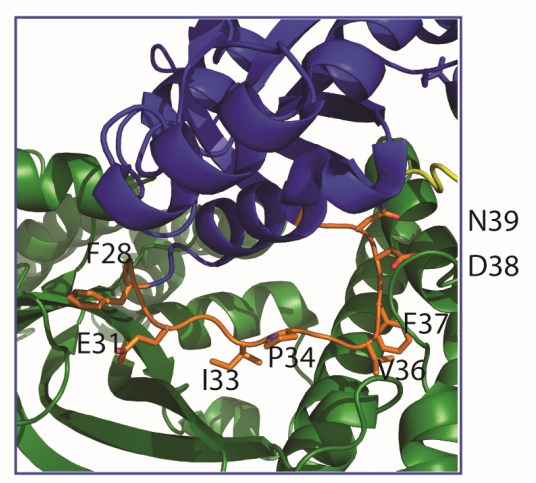

F DOCK inhibtory peptides

R R R R C W A R Y H G Y P W C R R R R

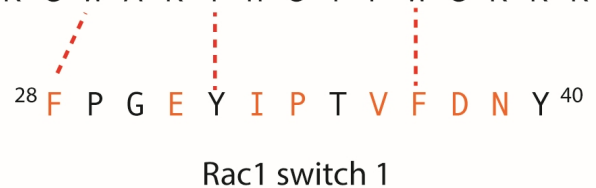

Rac1 switch 1

Figure 4 
A

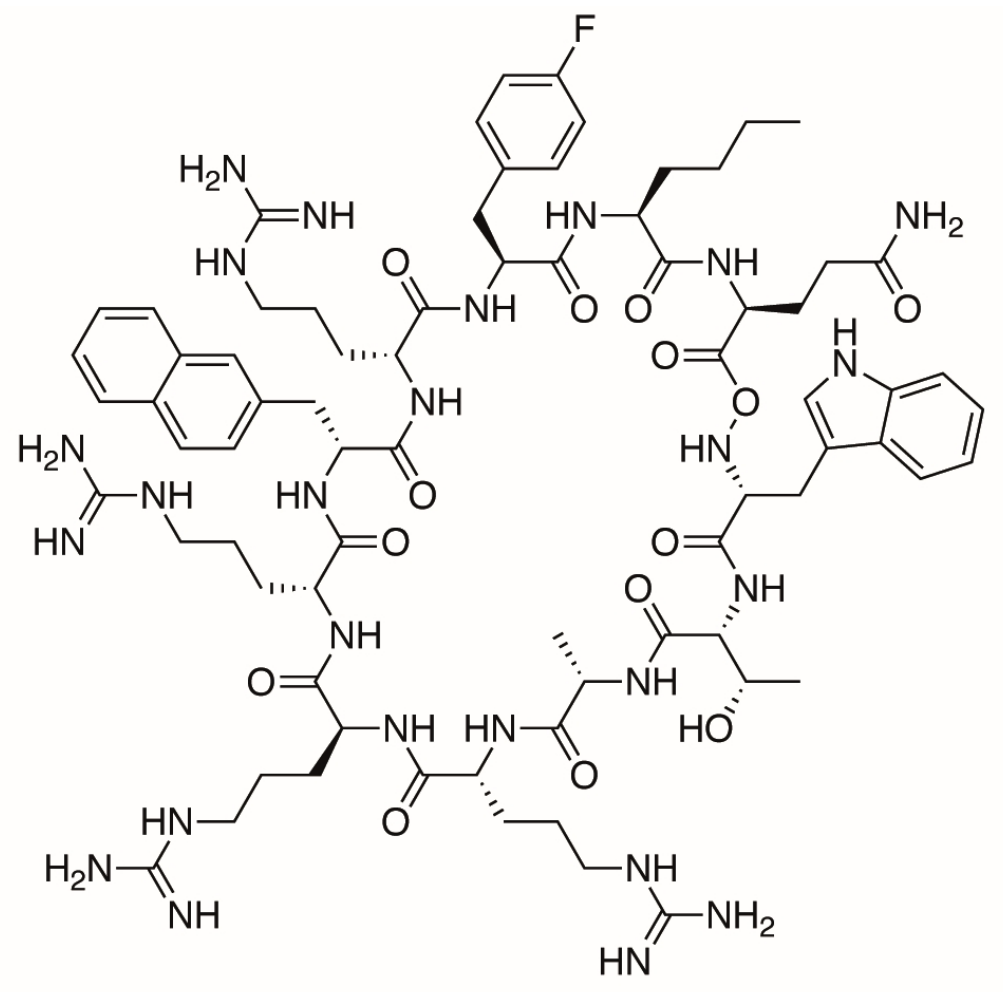

B

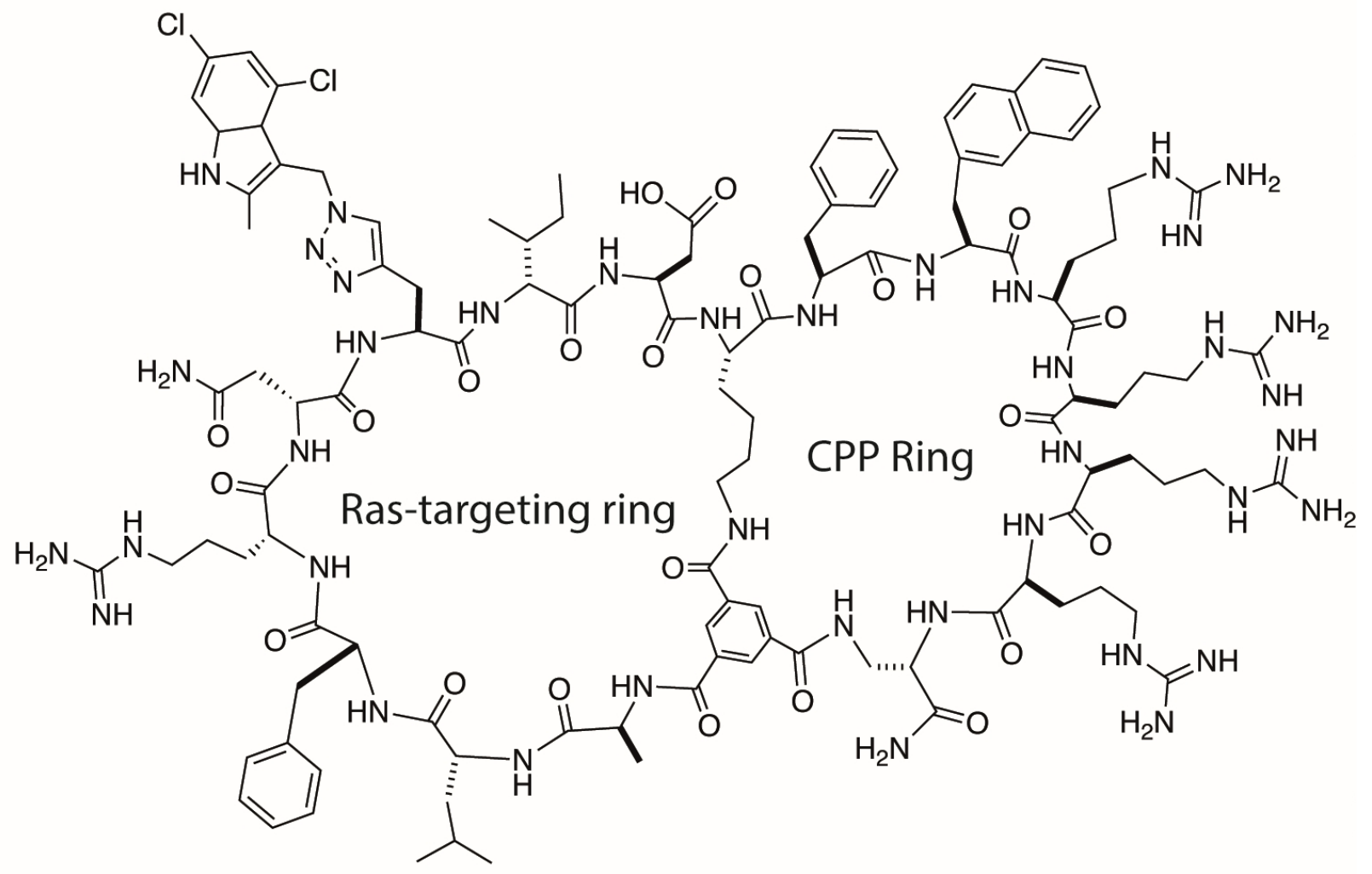

Figure 5 

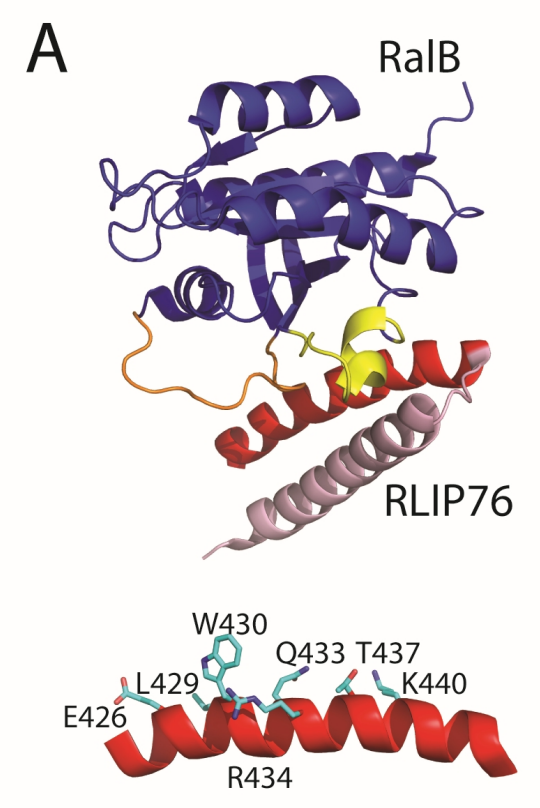

423 L S KE E R L W ${ }^{*}$ E V Q R I L TA L KRKLRE ${ }_{446}^{*}$
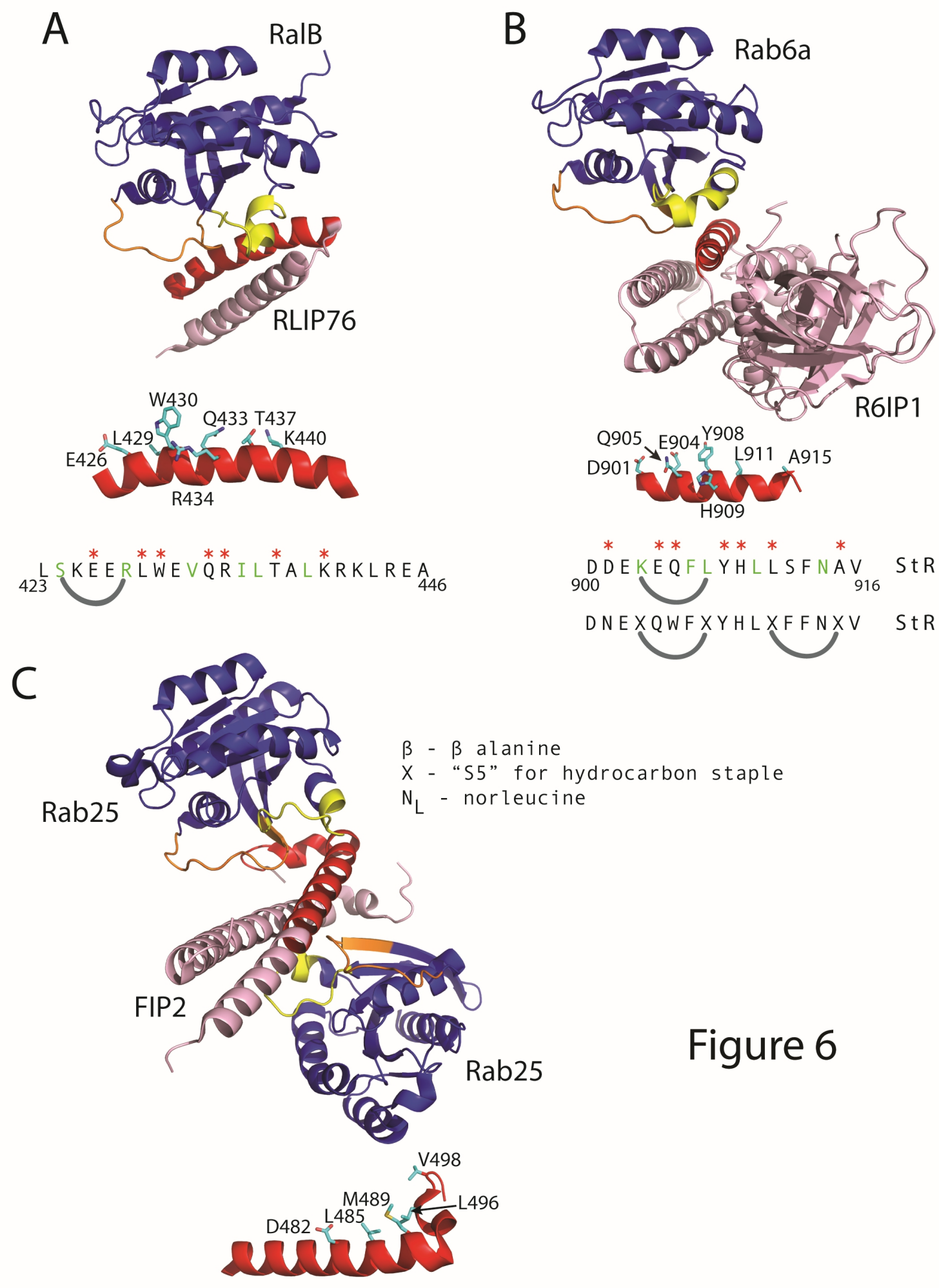

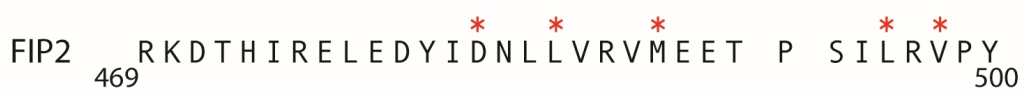

FIP1 $\underset{1243}{\text { KKEFQVRELEDYIDNLLVRVMEET P NILRIPA }}{ }_{1274}^{A}$

FIP3 ${ }_{726}$ KQEEINFRLQDYIDRIIVAIMETN P SILEVK RFP14 $\quad$ BRQVRELENYIDRLLVXVNEXT P NILRIPR $\alpha$-helix turn $3_{10}$ helix 
A

B

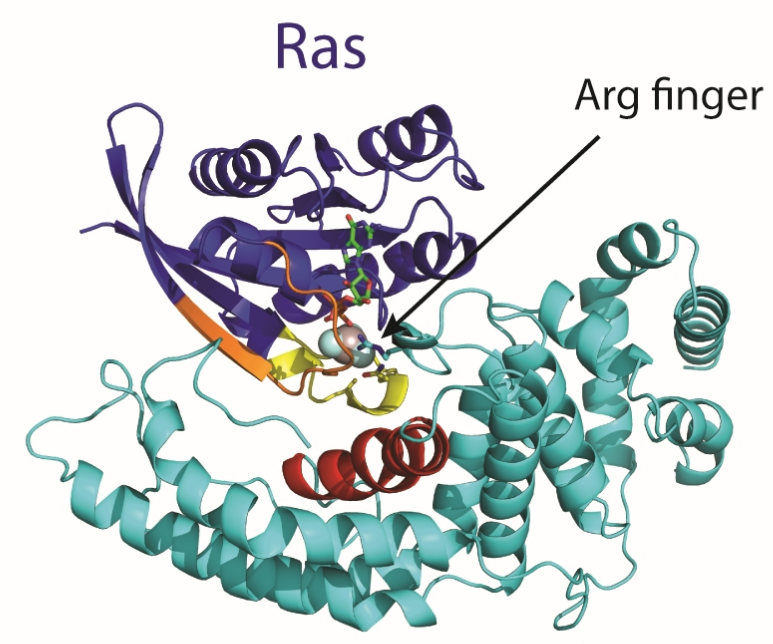

Ras

RasGAP

Figure 7

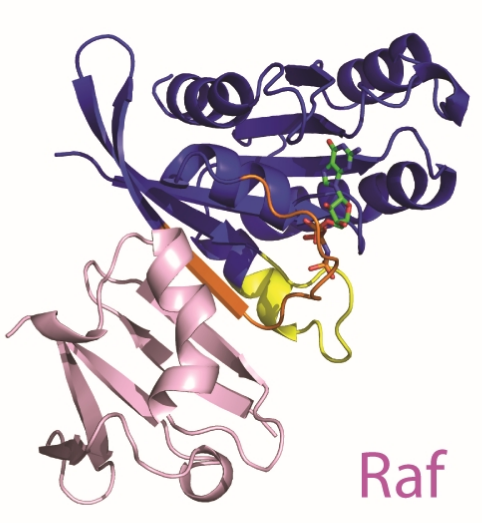

